NIST Technical Note 1457

\title{
FY2003 Annual Report Next Generation Fire Suppression Technology Program (NGP)
}

Richard G. Gann

National Institute of Standards and Technology • Technology Administration • U.S. Department of Commerce 


\section{NIST Technical Note 1457}

\section{FY2003 Annual Report Next Generation Fire Suppression Technology Program (NGP)}

Richard G. Gann

Building and Fire Research Laboratory

January 2004

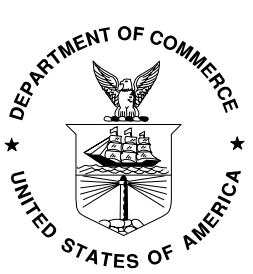

U.S. Department of Commerce Donald L. Evans, Secretary

Technology Administration

Phillip J. Bond, Under Secretary for Technology

National Institute of Standards and Technology

Arden L. Bement, Jr., Director 
Certain commercial entities, equipment, or materials may be identified in this document in order to describe an experimental procedure or concept adequately. Such identification is not intended to imply recommendation or endorsement by the National Institute of Standards and Technology, nor is it intended to imply that the entities, materials, or equipment are necessarily the best available for the purpose.

National Institute of Standards and Technology Technical Note 1457

Natl. Inst. Stand. Technical Note 1457, 46 pages (January 2004)

CODEN: NSPUE2

For sale by the Superintendent of Documents, U.S. Government Printing Office Internet: bookstore.gpo.gov — Phone: (202) 512-1800 - Fax: (202) 512-2250 Mail: Stop SSOP, Washington, DC 20402-0001 

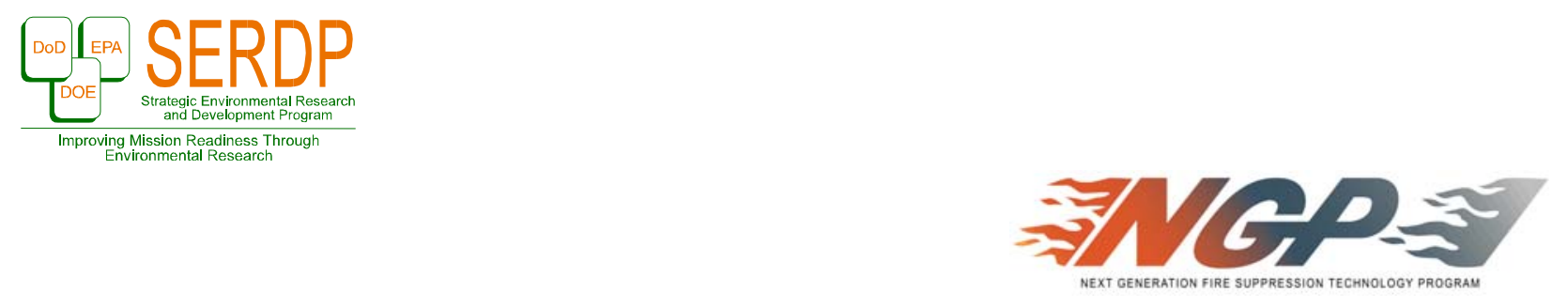

FY2003 ANNUAL REPORT

\section{Next Generation Fire Suppression Technology Program (NGP) [PP-1059] January 2004}

Richard G. Gann, Ph.D.

Technical Program Manager 
This page intentionally left blank. 


\section{ABSTRACT}

The Department of Defense's Next Generation Fire Suppression Technology Program (NGP) has completed its seventh year of research with a goal to develop and demonstrate technology for economically feasible, environmentally acceptable and user-safe processes, techniques, and fluids that meet the operational requirements currently satisfied by halon 1301 systems in aircraft.

Research on new flame suppression chemistry and improved suppressant delivery has produced substantive results.

The NGP is supported by the DoD Strategic Environmental Research and Development Program (SERDP).

Keywords: fire research, fire suppression, halon, aircraft 
This page intentionally left blank. 


\section{TABLE OF CONTENTS}

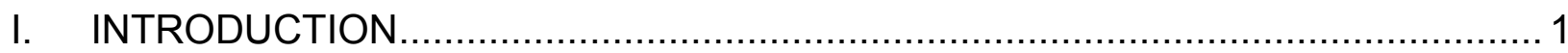

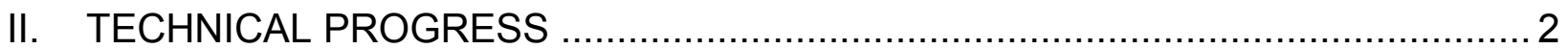

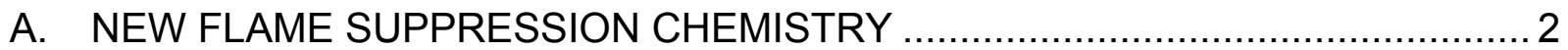

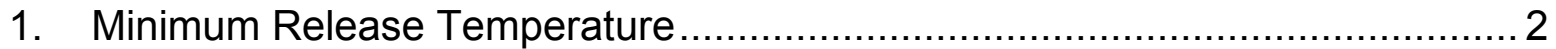

2. Vapor Loading and Suppression Effectiveness of Two-phase Fire

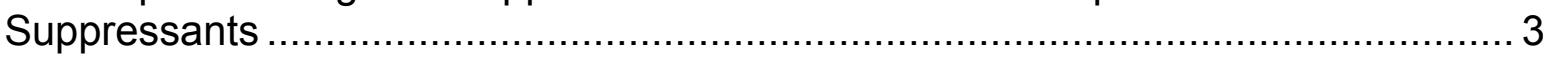

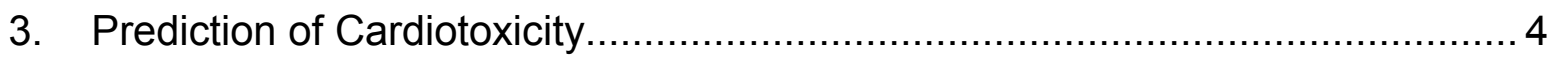

4. New Candidate Suppressants.............................................................. 5

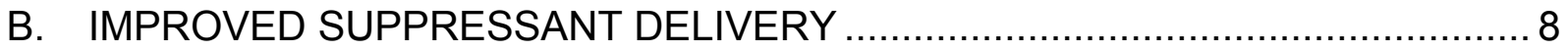

1. Solid Propellant Fire Extinguishers (SPFEs) …..................................... 8

2. Dispersion of Suppressants at Low Temperature ..................................... 10

3. Suppressant Dynamics in Engine Nacelles …….................................... 11

4. Enhanced Powder Panels for Dry Bay Fire Protection................................. 21

C. VIABILITY OF NEW SUPPRESSANT TECHNOLOGIES ….......................... 25

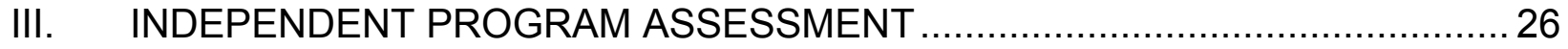

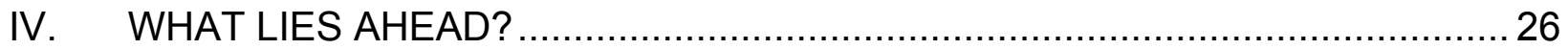

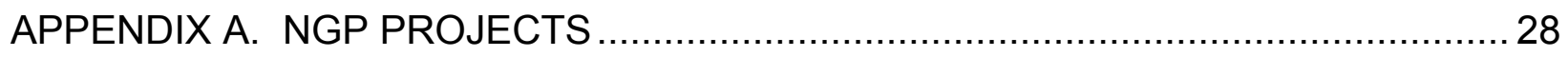

APPENDIX B. REPORT OF THE INDEPENDENT REVIEW PANEL ........................ 31 
This page intentionally left blank. 


\section{INTRODUCTION}

Initiated in 1997, the Department of Defense's Next Generation Fire Suppression Technology Program (NGP) has completed its seventh year of research with considerable accomplishment. Supported by the DoD Strategic Environmental Research and Development Program (SERDP), the NGP goal is to "Develop and demonstrate technology for economically feasible, environmentally acceptable and user-safe processes, techniques, and fluids that meet the operational requirements currently satisfied by halon 1301 systems in aircraft."

Fires and explosions continue to be among the greatest threats to the safety of personnel and the survivability of military aircraft both in peacetime and during combat operations. Production of halon $1301\left(\mathrm{CF}_{3} \mathrm{Br}\right)$, long the fire suppressant of choice, ceased as of January 1, 1994 due to its high ozone depleting potential (ODP). By 1997 the DoD had identified the best available replacement for halon 1301 in aircraft, HFC-125 $\left(\mathrm{C}_{2} \mathrm{H}_{5} \mathrm{~F}\right)^{1}$, but it requires two to three times the mass and storage volume and contributes to global warming. The new Program was to identify fire suppression technologies with reduced compromises.

While research to identify replacement suppressants for engine nacelle and dry bay fires has declined considerably over the past five years, the demand for new approaches is unabated. New aircraft are in various stages of design. No commercial or military aircraft have yet had their halon 1301 systems replaced, while new systems are being installed in the cargo bays of commercial jetliners. The international community is questioning the necessity of maintaining the large halon 1301 reserves and even considering the requirement of a total phaseout.

The demands on the new technologies remain daunting. The requirements for environmental protection, fire suppression efficiency, materials compatibility, and personnel safety are severe constraints.

The presentation of technical progress and new products and the genesis of ideas have been abetted by the Halon Options Technical Working Conferences, founded in 1991. In 2002, the NGP assumed responsibility for these workshops. The cumulative papers have been indexed and are available on CD and at www.bfrl.nist.gov/866/HOTWC.

The systematic NGP search for new suppressant chemicals and technologies for assured, efficient delivery is continuing to produce new results. During the past year, an Independent Review Panel (IRP) was "Impressed by the thoughtful way the 2001 recommendations have been addressed and by the tightened focus of the program" and "confident that valuable design products will be delivered by this program." Their sole new recommendation will be implemented in FY2004.

The NGP participants have generated unparalleled contributions to the published literature in the field, all of which can be obtained via the NGP web site: www.bfrl.nist.gov/866/NGP. The following pages highlight the new knowledge gained from the NGP research and the progress made towards the NGP Goal. Recent publications are listed at the end of each research topic. A concluding section forecasts where the research will proceed from this time forward. Two appendices list the NGP projects to date and present the latest IRP report.

\footnotetext{
${ }^{1}$ Technology Development Plan for Alternatives to Ozone-depleting Substances for Weapons Systems Use; Final Report (TDP), Office of the Deputy Undersecretary of Defense (Science and Technology)/Weapons Systems, 1998.
} 


\section{TECHNICAL PROGRESS}

\section{A. NEW FLAME SUPPRESSION CHEMISTRY}

In prior years, the NGP had developed a new understanding of how efficient chemicals interact with flames and eventually suppress them. This is summarized as follows:

Flame propagation results from the fast reactions of key species $(\mathrm{H}$ and $\mathrm{O}$ atoms, $\mathrm{OH}$ radicals) with vaporized fuel molecules. These species exist at concentrations far above those expected from thermal equilibrium at flame temperatures. Chemically active agents catalytically reduce the radical concentrations toward equilibrium levels. While this process slows the flame, it does not extinguish it. The suppressant also increases the heat capacity of the fuel/air mixture, reducing the flame temperature and thus the flame reaction rates below the level needed to sustain combustion. These two effects are synergistic. The need for both effects suggests that the lower limit for a suppression concentration may be at about $1 \%$ by volume.

With this knowledge the NGP had developed a list of criteria to guide the search:

1. Fire suppression efficiency at least comparable to halon 1301 (about $3 \%$ by volume) and certainly higher than the hydrofluorocarbons (HFCs). Based on prior experience, this focuses the search on compounds that contain at least one bromine, iodine or phosphorus atom, although other possible functionalities can arise. (See Section II.A.4.)

2. Short atmospheric lifetime (current preference of the order of a month), to keep ozone depletion potential (ODP), global warming potential (GWP) and any future unidentified environmental contamination issues to a minimum.

3. Boiling point sufficiently low that for gaseous agents, an extinguishing concentration can be achieved within a specified time following discharge. An approximate theoretical upper limit is near $30^{\circ} \mathrm{C}$ if the minimum temperature in flight is $-40^{\circ} \mathrm{C}$.

4. Low toxicity relative to the concentration needed for suppression.

\section{Minimum Release Temperature}

With regard to criterion 3, an effort is underway to improve understanding of the actual aircraft temperatures at which halon 1301 has been deployed. Incorporating the chemical features that effect low atmospheric lifetime (criterion 2) generally results in molecules that are larger than halon 1301 and thus tends toward higher boiling points, $T_{b}$. As $T_{b}$ rises, there are more compounds per, e.g., $10^{\circ} \mathrm{C}$ band, so the domain of eligible chemicals increases significantly.

Data from incidents of halon release from all three services have been gathered. They document the altitude at which each release occurred, and we are converting this to an approximate temperature. Consideration is also being given to aircraft operating in cold climates, where the limiting temperature for suppressant release during take-off may be close to the (low) ground temperature. Completion of this task is expected in winter 2003-2004. The results, combined with those from Section II.A.2 of this Report, will help refine the selection criterion for agent volatility, provide guidance to the dispersion optimization project presented in Section II.B, and assist platform managers in their selection of suppressant for their particular aircraft. 


\section{Vapor Loading and Suppression Effectiveness of Two-phase Fire Suppressants}

A rapidly released suppressant fluid disperses partially as droplets and partially as a gas. The high momentum droplets can fill a volume rapidly. For halon 1301, the droplets flash vaporize, completing the efficient dispersion of a gaseous suppressant. Thus all of the suppressant contributes to the effective concentration at the fire zone.

For a chemical with a higher boiling point and/or a higher heat of vaporization, more of the fluid reaching the fire may still be in the liquid phase. Larger droplets may impact and stick to cold surfaces, may not flash vaporize en route to the flames, and also may pass through the flames without vaporizing fully. Thus, some (or even much) of the agent may not contribute to the effective concentration in the fire zone. To compensate for this, the mass of the fire suppression system may need to be increased significantly, either by carrying a larger mass of agent or by heating the storage and delivery hardware.

Thus, given knowledge of the (low) ambient temperature, it is important to be able to estimate the true effective concentration of a potential halon alternative. This involves droplet evaporation time, flame zone residence time, and saturation vapor pressure.

We are in the process of simulating the degree of vaporization of various aerosols in a simulated engine nacelle and developing criteria for the physical properties that lead to an acceptable suppression efficiency. The chosen computational code is the Fire Dynamics Simulator. The computational test environment is the simple engine nacelle ELEFANT developed under the NGP and described in previous NGP Annual Reports. The input conditions for the engine nacelle reflect an expected range of agent deployment conditions:

- Incoming air temperatures from ambient ( $c a .298 \mathrm{~K}$ ) down to $233 \mathrm{~K}$.

- Nacelle interior temperatures from ambient (298 K at startup) to $373 \mathrm{~K}$.

- Input air flow velocity of $1 \mathrm{~m} / \mathrm{s}$.

- Mean drop size of $c a .20 \mu \mathrm{m}$ for the polydisperse mist drop distribution immediately after agent release.

- Vapor fraction immediately following release of the pressurized agent (given by the Jacob number) between 0.2 and 0.7 . The Jacob number relates a compound's heat capacity to its heat of vaporization. Since a compound's heat of vaporization is generally tied to its boiling point (via Trouton's rule), the Jacob Number computational range essentially determines the range of physical properties for the test liquids.

We have completed computations for water droplets under ambient temperature conditions for incoming air and for all surfaces inside the nacelle either at ambient temperature or at $373 \mathrm{~K}$. Assessment of the preliminary findings is underway and will likely result in tuning of the computational scheme. The remaining simulations covering the matrix of physical parameters dictated by the Jacob number will be completed within the next two months. Then we will perform calculations for actual compounds with properties that closely match those parameters determined to result in the most success. This will be combined with the results from our examination of chemical families, resulting in a list of compounds that are likely to lead to effective fire suppression at low operation temperatures. 


\section{Prediction of Cardiotoxicity}

Sensitization to cardiac arrhythmia is recognized as the primary (but not only) toxic effect of the halogenated compounds that dominate the search for halon alternatives. The cost of the standard dog exposure test to determine a compound's LOAEL can reach $\$ 100 \mathrm{k}$ for custom-synthesized chemicals. Hence, estimating the cardiac sensitization LOAEL for a single compound or the relative LOAEL values of a series of related compounds can have a major impact on whether an effective and safe alternative suppressant is identified. The NGP is monitoring and evaluating research into methods based on both physical properties and in vitro testing.

Partition Coefficients. A wide range of chemically diverse compounds are known to induce cardiac arrhythmia. This situation has led to the hypothesis that the mechanism involved is not a chemical (reactivity based) toxicity but instead a generalized physical property effect that just happens to cause cardiac arrhythmia when sufficient chemical is absorbed into heart nerve and muscle cells membranes. The hypothesis suggests that if a chemical is preferentially soluble in a barely polar liquid such as octanol, and less soluble in a polar fluid such as water, it is less likely to be flushed from the tissue environment. Determination of the octanol-water partition coefficient, $\mathrm{K}_{\mathrm{OW}}$, is rapid and requires only a few $\mathrm{mg}$ of the compound.

Examining the quality of correlation between $\mathrm{K}_{\mathrm{OW}}$ values and LOAEL values requires a database for members of a given chemical family. While there are calculation and experimental methods to determine the former, there are far less data on the latter. One chemical family for which such data exist is that of volatile anesthesia gases where the need for quick induction, low toxicity, and quick recovery with few side effects has driven extensive research. Table 1 shows the results of measurements for several of these halon-like compounds. Halothane $\left(\mathrm{CF}_{3} \mathrm{CBrClH}\right)$ is prone to causing premature ventricular contractions (PVCs). The alternative anesthetics have progressively lower tendencies to induce PVCs and also progressively lower oil-water distribution ratios when compared to halothane. This correlation is worth further study and at least preliminary examination as a means of guiding the selection of halon replacement candidate compounds.

In Vitro Cardiac Sensitization Screening Methods. We are monitoring the progress of a proposal (to another Federal agency) for the development of an in vitro method using human or animal cardiomyocytes with applicability to the testing of volatile compounds and generation of relative cardiotoxicty data. If successful, this screening method would improve the identification of suppressants with acceptably low cardiac sensitization properties. 
Table 1. Anesthesia Compounds - Partitioning and Arrhythmia Properties ${ }^{2,3}$

\begin{tabular}{|l|c|c|c|c|c|}
\hline \multicolumn{1}{|c|}{ Property } & Halothane & Enflurane & Isoflurane & Desflurane & Sevoflurane \\
\hline Blood-gas Ratio $^{\mathrm{a}}$ & 2.5 & 1.9 & 1.4 & 0.42 & 0.6 \\
\hline Oil-water Ratio $^{\mathrm{b}}$ & 220 & 120 & 170 & 19 & 55 \\
\hline Arrhythmia $^{\mathrm{c}}$ & +++ & + & + & $\sim$ & $\sim$ \\
\hline MAC $^{\mathrm{d}}$ & $0.74 \%$ & $1.68 \%$ & $1.15 \%$ & $6.3 \%$ & $2.0 \%$ \\
\hline
\end{tabular}

a Ratio of the anesthesia agent concentration in the blood over the anesthesia agent concentration in the gas phase. High values indicate more effective transport of the chemical throughout the body and thus to cardiac tissue.

b The "oil" phase is commonly, but not exclusively, octanol.

c The symbols "+++," "+," and " " reflect, in order, a decreasing tendency of the anesthetic to induce PVCs in human patients during anesthesia. The last of these indicates only a slight tendency.

${ }^{\mathrm{d}}$ Minimum Alveolar (air) Concentration (MAC) for an anesthesia agent is a measure of the anesthetic potency of the compound, i.e., the air concentration required to immobilize $50 \%$ of patients such that they don't give a motor response to a pain stimulus.

\section{New Candidate Suppressants}

The current phase of the examination of chemical families for potential $\mathrm{CF}_{3} \mathrm{Br}$ replacements is following the general guidance from the most recent assessment of the field. ${ }^{4}$ The priorities are summarized in Table 2. The effort has led to the identification of promising directions likely to meet flame suppression needs and possibly toxicity and environmental goals. The compounds identified are being sourced and will have their cup burner flame suppression performance determined. The boiling points of some are predicted to be in the $0{ }^{\circ} \mathrm{C}$ to $10^{\circ} \mathrm{C}$ range and as such represent some of the lowest boiling compounds yet tested.

Last year, the NGP commissioned the synthesis of a series of eight phosphorus-containing compounds (PCCs). Of the seven that could be synthesized, four appeared to be stable.

However, despite substantial fluorination, the lowest $\mathrm{T}_{\mathrm{b}}$ was $42{ }^{\circ} \mathrm{C}$. Thus, further examination of the PCCs awaits resolution of the boiling point criterion.

Because of their high flame inhibition efficiency, metal-containing compounds continue to be of interest for possible use as suppression enhancers, e.g., in gas generators and powder panels. However, alkali metal compounds are corrosive to aluminum in moist environments and two iron-containing compounds have been found to be ineffective at fire suppression or too toxic for such use. To determine whether there is reason to pursue the metal-containing compounds further, The NGP is investigating:

\footnotetext{
${ }^{2}$ Hemmings, H. Jr., and Hopkins, P., Foundations of Anesthesia - Basic and Clinical Sciences, Chapters 24 and 41 , Harcourt Publishers Ltd., 2000.

${ }^{3}$ www.virtual-anaesthesia-textbook.com/vat/volatile.htm. This is an excellent tutorial website with detailed discussions of a wide variety of anesthesia agents including clinical human exposure and cardiac effects information as well as further reference citations.

${ }^{4}$ Tapscott, R.E., Sheinson, R.S., Babushok, V., Nyden, M.R., Gann, R.G., "Alternative Fire Suppressant Chemicals: A Research Review with Recommendations," NIST Technical Note 1443, National institute of Standards and Technology, Gaithersburg MD, 2001.
} 
- The features that lead to effective chemical action in quenching flame chemistry and

- The features that can limit the concentration of the active species in the flame zone.

Recognizing the importance of the binding energy of a suppressant to one of the free radicals that participate in the chain branching chemistry of flame propagation, we have conducted computation studies to elucidate the specific desirable values. The test bed was a stoichiometric methane-air mixture. Based on prior studies, the examples investigated were the binding of bromine and hydrogen atoms, sodium with hydroxyl radicals and iron with oxygen atoms. The binding energies were varied about the accepted values, and the resulting effect on the flame velocity was assessed. In all three cases, the largest reduction in flame velocity occurred at or very near the actual bond energy. It was concluded that the bond energy between a catalytic scavenger and a flame radical must be in the range of $300 \mathrm{~kJ} / \mathrm{mole}$ to $400 \mathrm{~kJ} / \mathrm{mole}$. Work in the coming year will examine properties that can cap the effectiveness of flame suppressants.

Table 2. Prioritized Potential Halon Replacement Families

\begin{tabular}{|l|c|c|c|}
\hline \multirow{2}{*}{\multicolumn{1}{c|}{ Chemical Family }} & \multicolumn{2}{c|}{ Recommendation } \\
\cline { 2 - 4 } & High Priority & Further Study & Quick Look \\
\hline Iodine-containing alkanes and alkenes & & $\mathrm{X}$ & \\
\hline Bromine-containing alkenes & $\mathrm{X}$ & & \\
\hline Iodine-containing ethers & & & $\mathrm{X}$ \\
\hline Bromine-containing ethers & & & $\mathrm{X}$ \\
\hline Bromine-containing alcohols & & $\mathrm{X}$ & \\
\hline Fluorine-containing aldehydes and ketones & & & $\mathrm{X}$ \\
\hline Nitriles & $\mathrm{X}$ & & \\
\hline Fluoro- and bromofluoroamines & & & $\mathrm{X}$ \\
\hline Sulfoxides & $\mathrm{X}$ & & \\
\hline Phosphorus-containing acids and esters & & $\mathrm{X}$ & \\
\hline Phosphonitriles and phosphorus halides & & & $\mathrm{X}$ \\
\hline Copper-containing compounds & $\mathrm{X}$ & & \\
\hline Manganese- or tin-containing compounds & & $\mathrm{X}$ & \\
\hline Iron-containing compounds & & & \\
\hline
\end{tabular}

To keep boiling points low and fire suppression efficiency high, attention has been focused on fluorinated, generally bromine-containing compounds. The nitrile group $(-\mathrm{CN})$ has been described as a "pseudohalogen," so compounds containing this functionality are being explored as well. In particular, members of the following families are in the process of being acquired for flame extinguishment testing:

- Fluoronitiriles and bromofluoronitriles. The first fluoronitriles and bromofluoronitriles being acquired represent the expected lowest boiling compounds from these two groups and are readily available commercially. Trifluoroacetonitrile $\left(\mathrm{CF}_{3} \mathrm{CN}\right)$ has a $\mathrm{T}_{\mathrm{b}}$ of $-64^{\circ} \mathrm{C}$. 
The flame extinguishment performance for this chemical and the full family is unknown, so this result could open an unanticipated direction for a new candidate.

Bromodifluoroacetonitrile $\left(\mathrm{CF}_{2} \mathrm{BrCN}\right)$ is expected to have a suppression efficiency at least comparable to halon 1301 . Its $\mathrm{T}_{\mathrm{b}}$ is only $3{ }^{\circ} \mathrm{C}$. The atmospheric lifetimes of the nitriles are expected to be limited by hydrolysis of the $\mathrm{CN}$ group and rainout.

- Bromofluoropropene oxides. These compounds are expected to be stable under storage and will likely decompose readily in the flame front to liberate the chemical fire suppressing bromine atom. Their atmospheric lifetimes are expected to be short, but this needs to be confirmed. Cup burner values for the monobrominated compounds should be similar to halon 1301, with specific values possibly reflecting the location of the bromine in the molecule. Boiling points for the bromoperfluoropropene oxides (oxiranes) are estimated to be between $0{ }^{\circ} \mathrm{C}$ and $10^{\circ} \mathrm{C}$. They can be synthesized in a single step from existing bromofluoropropenes by a partial oxidation of the alkene bond. $\mathrm{CF}_{2}(\mathrm{O}) \mathrm{CFCF}_{2} \mathrm{Br}$ (3-bromo-1,2-perfluoropropene oxide), $\mathrm{CF}_{2}(\mathrm{O}) \mathrm{CBrCF}_{3}$ (2-bromo-1,2-perfluoropropene oxide), and $\mathrm{CFBr}(\mathrm{O}) \mathrm{CFCF}_{3}$ (-bromo-1,2-perfluoropropene oxide) are being sourced.

- Bromofluoropropenes. The atmospheric lifetimes of these compounds should be low since the double bond is reactive in the troposphere. $\log \mathrm{K}_{\mathrm{OW}}$ values were calculated, using several available modeling methods, for the 35 possible penta-, tetra- and trifluorinated bromofluoropropenes. The values obtained from some of the methods varied considerably, indicating that that calculation method was sensitive to structural changes. Overall, the calculated $\log \mathrm{K}_{\mathrm{OW}}$ values ranged from 1.4 to 2.5. Using the experimental $\mathrm{K}_{\mathrm{OW}}$ value of 1.84 for halon 1301 as a guide, a list of compounds whose low calculated values predicted a possibly equivalent or higher LOAEL was prepared and is shown in Table 3. Two other partially fluorinated compounds have demonstrated unacceptably low LOAEL values for cardiac sensitization, but the values for the compounds in Table 3 have not been measured. We are also seeking to obtain the three fully halogenated compounds with the lowest calculated $\mathrm{K}_{\mathrm{Ow}}$ values: $\mathrm{CFBr}=\mathrm{CFCF}_{3}$ (1-bromoperfluoropropene, $\mathrm{T}_{\mathrm{b}}=27^{\circ} \mathrm{C}$ ), $\mathrm{CF}_{2}=\mathrm{CBrCF}_{3}$ (2-bromoperfluoropropene, $\mathrm{T}_{\mathrm{b}}=25^{\circ} \mathrm{C}$ ), and $\mathrm{CF}_{2}=\mathrm{CFCF}_{2} \mathrm{Br}$ (3-bromoperfluoropropene).

- Bromofluoroethers. They are expected to have relatively low toxicity and good flame extinguishment properties but unless they prove sufficiently polar they will require some degree of hydrogenation to minimize ODP impact. Two of the simplest brominated ethers are $\mathrm{CBrH}_{2}-\mathrm{O}-\mathrm{CF}_{3}\left(\mathrm{~T}_{\mathrm{b}}=39^{\circ} \mathrm{C}\right)$ and $\mathrm{CBrF}_{2}-\mathrm{O}-\mathrm{CF}_{3},\left(\mathrm{~T}_{\mathrm{b}}\right.$ estimated between $-30{ }^{\circ} \mathrm{C}$ and $-8{ }^{\circ} \mathrm{C}$ ). The tetrafluorinated $\mathrm{C}_{2}$ bromoethers $\mathrm{CBrHF}-\mathrm{O}-\mathrm{CF}_{3}$ (bromofluoromethyl trifluoromethyl ether) and $\mathrm{CBrF}_{2}-\mathrm{O}-\mathrm{CHF}_{2}$ (bromodifluoromethyl difluoromethyl ether) are predicted to boil in the range $5{ }^{\circ} \mathrm{C}$ to $15^{\circ} \mathrm{C}$ and are being sought for testing. $\mathrm{CBrF}_{2}-$ $\mathrm{O}_{-} \mathrm{CF}_{3}$, (bromodifluoromethyl trifluoromethyl ether) is also being sought. 
Table 3. Low Kow Bromofluoropropenes

\begin{tabular}{|c|c|c|}
\hline Compound & Name & Cis-, trans-isomerism \\
\hline $\mathrm{CF}_{2}=\mathrm{CFCF}_{2} \mathrm{Br}$ & 3-bromo-pentafluoropropene & \\
\hline $\mathrm{CF}_{2}=\mathrm{CBrCF}_{2} \mathrm{H}$ & 2-bromo-1,1,3,3-tetrafluoropropene & \\
\hline $\mathrm{CFBr}=\mathrm{CFCF}_{2} \mathrm{H}$ & 1-bromo-1,2,3,3-tetrafluoropropene & $\mathrm{Y}$ \\
\hline $\mathrm{CF}_{2}=\mathrm{CFCFHBr}$ & 3-bromo-1,1,2,3-tetrafluoropropene & \\
\hline $\mathrm{CF}_{2}=\mathrm{CHCF}_{2} \mathrm{Br}$ & 3-bromo-1,1,3,3-tetrafluoropropene & \\
\hline $\mathrm{CF}_{2}=\mathrm{CBrCFH}_{2}$ & 2-bromo-1,1,3-trifluoropropene & \\
\hline $\mathrm{CFH}=\mathrm{CBrCF}_{2} \mathrm{H}$ & 2-bromo-1,3,3-trifluoropropene & $\mathrm{Y}$ \\
\hline $\mathrm{CF}_{2}=\mathrm{CFCBrH}_{2}$ & 3-bromo-1,1,2-trifluoropropene & \\
\hline $\mathrm{CFH}=\mathrm{CFCFBrH}$ & 3-bromo-1,2,3-trifluoropropene & $\mathrm{Y}$ \\
\hline $\mathrm{CF}_{2}=\mathrm{CHCFBrH}$ & 3-bromo-1,1,3-trifluoropropene & \\
\hline $\mathrm{CFH}=\mathrm{CHCBrF}_{2}$ & 3-bromo-1,3,3-trifluoropropene & Y \\
\hline $\mathrm{CFBr}=\mathrm{CFCFH}_{2}$ & 1-bromo-1,2,3-trifluoropropene & $\mathrm{Y}$ \\
\hline $\mathrm{CBrF}=\mathrm{CHCHF}_{2}$ & 1-bromo-1,3,3-trifluoropropene & $\mathrm{Y}$ \\
\hline $\mathrm{CHBr}=\mathrm{CFCHF}_{2}$ & 1-bromo-2,3,3-trifluoropropene & $\mathrm{Y}$ \\
\hline
\end{tabular}

\section{Recent Publications: New Flame Suppression Chemistry}

Shreeve, J.M., Singh, R.P., Tapscott, R.E., and Mather, J.D., Fluoroalkyl Phosphorus Compounds, Final Report to SERDP, Report 2003/1/34501, New Mexico Engineering Research Institute, Albuquerque, NM, 2003.

Williams, B.A., and Fleming, J.W., "Influence of Bond Energies on Catalytic Flame Inhibition: Implications for the Search for New Fire Suppressants," NRL/MR/6180--03-8728, Naval Research Laboratory, Washington DC, 2003.

Mather, J.D., and Tapscott, R.E., "Tropodegradable and Other Environmentally Acceptable Flame Extinguishants," in Gann, R.G., Burgess, S.R., and Reneke, P.A., eds., Papers from 19912003 Halon Options Technical Working Conferences (HOTWC), CD-ROM, NIST SP 984-1, National Institute of Standards and Technology, Gaithersburg, MD, 2003.

\section{B. IMPROVED SUPPRESSANT DELIVERY}

\section{Solid Propellant Fire Extinguishers (SPFEs)}

Prior NGP research had developed new types of solid propellant fire extinguishers that have both reduced combustion temperatures and increased flame suppression efficiency, which in turn will enable freedom of selection of the momentum of the suppressant stream. These have now been examined further.

The combination of propellants based on the advanced high nitrogen propellant BTATZ $\left(\mathrm{C}_{4} \mathrm{H}_{4} \mathrm{~N}_{14}\right)$ and incorporation of coolant species into the propellant composition reduces exhaust 
temperatures by as much as $30 \% v s$. current baselines. The incorporation of potassium carbonate in the solid propellant composition decreases by up to a factor of three the mass of suppressant needed to extinguish mid-scale flames. Fire testing using hybrid fire extinguisher (HFE) configurations, in which the coolant or chemical additive is added downstream of the combusting propellant, showed that high-boiling agents can be delivered even at low temperatures, their low vapor pressures offset by the heating and pressurizing power of the solid propellant driven HFE. This has produced an additional $c a .30 \%$ increase in mass efficiency (Figure 1). Hydrofluorocarbons and hydrofluoroethers were comparably effective on a mass basis.

Figure 1. Side-by-Side Testing of Inert and Chemically Active (CA) SPFEs on Sub-scale (FTF) and Full-Scale Military Aircraft Platforms [blue bars: inert effluent, yellow bars: $1^{\text {st }}$ generation chemically active systems; green bars: $2^{\text {nd }}$ generation chemically active systems]

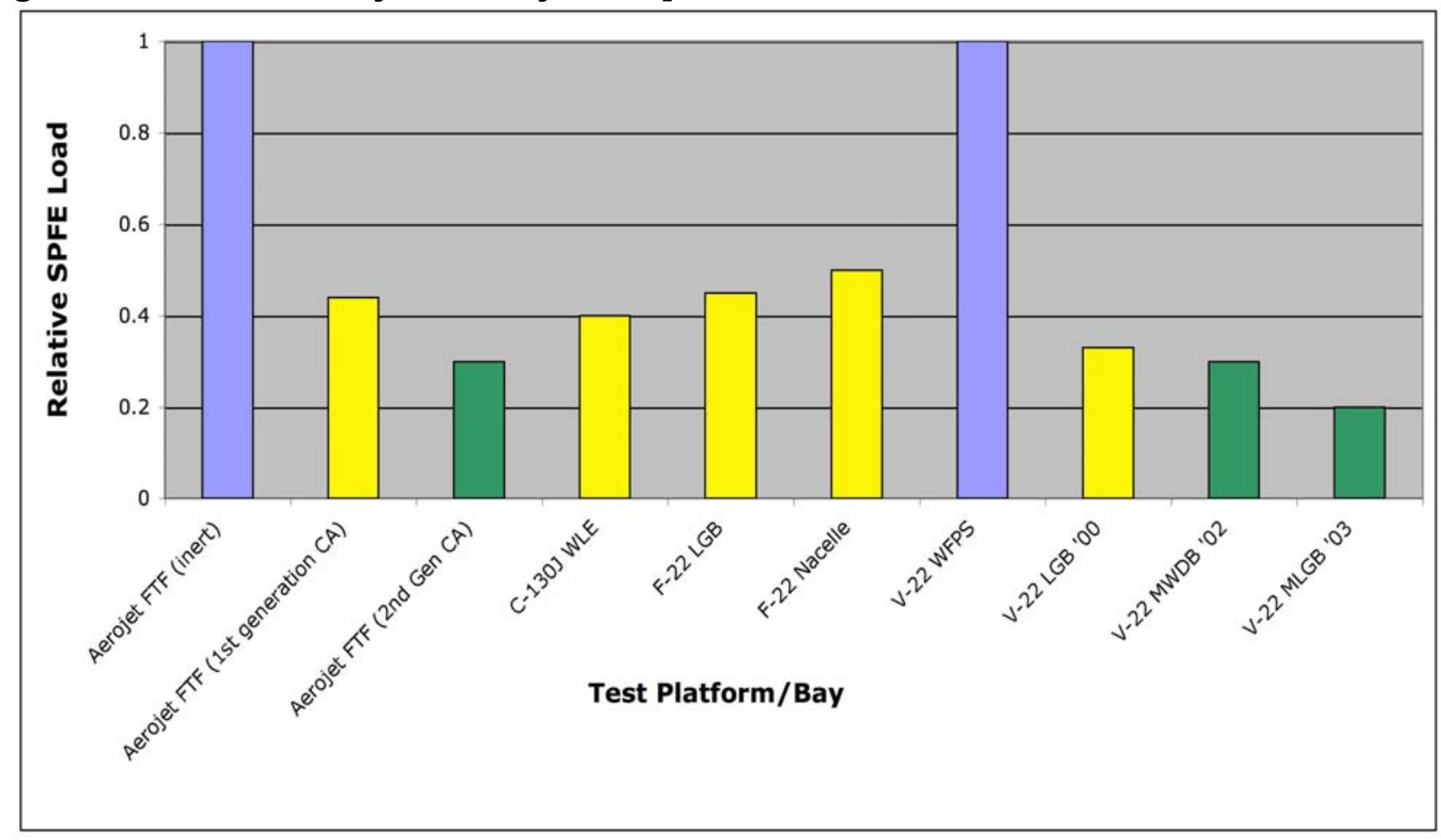

The SPFE technology examined under this NGP project is derived from fire protection products currently being installed on both the Navy F/A-18 E/F and V-22 aircraft. Our advanced fire suppression protection products incorporating improvements are currently being examined for further applications as expanded protection in the above platforms as well as on other aircraft platforms.

The dry bays and engine nacelles in military aircraft platforms vary significantly in size, air flow, and clutter, as evidenced in Table 4: 
Table 4. Representative Aircraft Test Platforms

\begin{tabular}{|l|c|l|c|}
\hline \multicolumn{1}{|c|}{ Platform } & Volume, $\mathbf{L}$ & Clutter & Airflow, $\mathbf{~ k g} / \mathbf{s}$ \\
\hline V-22 loss of lube bay & 280 & Min & $<1$ \\
\hline V-22 aft cove & 200 & High & $<1$ \\
\hline F-22 landing gear bay (LGB) & 700 & Moderate & $<1$ \\
\hline C-130 leading edge (WLE) & 1530 & Mod & $>4$ \\
\hline V-22 mid-wing dry bay (MWDB) & 4000 & High & $>4$ \\
\hline F/A-18 E/F engine bay & 1200 & Mod & $\approx 2$ \\
\hline F-22 engine nacelle & 2260 & Mod & $\approx 2$ \\
\hline
\end{tabular}

Several of the above platforms were used to evaluate the effectiveness of SPFE technology. These test series typically included side-by-side testing of both inert and chemically active SPFE systems. While these test series differed in bay size, clutter, airflow, fuel flow rate and pre-burn conditions (and therefore fire threat), the resulting threshold successful propellant masses show a consistent benefit.

These results show the validity both of the mid-scale test facility used to screen SFPE formulations and, more importantly, of the large improvements in efficiency from the NGPdeveloped SFPE technologies. The improved mass efficiency enables:

- Greater flexibility in design, which can translate into a reduced number of different SPFE configurations on a given aircraft, resulting in lower per unit costs and also lower logistics costs;

- Simplified existing fire protection system configuration by using a lesser number of different sizes of SPFEs; and

- Opportunities to upgrade fire protection system performance without substantive changes to the platform.

\section{Dispersion of Suppressants at Low Temperature}

NGP experiments with $\mathrm{CF}_{3} \mathrm{I}\left(\mathrm{T}_{\mathrm{b}}=-22^{\circ} \mathrm{C}\right)$ discharges into a simulated engine nacelle at $-40^{\circ} \mathrm{C}$ have shown that inefficient dispersion should be expected when discharging a suppressant fluid into a system whose temperature is well below the fluid boiling point. Much of the liquid deposited on the nacelle floor and evaporated over many seconds. Thus, basing the design mass of agent for an engine nacelle on room temperature test data could lead to significant underestimation of the mass needed for in-flight fire suppression. (See also Section II.A.2.)

Current work is directed at generalizing these results to a broader range of fluid boiling points and to different temperature differentials. The first task in doing this is to identify high boiling point chemicals. For these tests, the chemicals need not be effective fire suppressants, but they should meet the following criteria:

- Low toxicity, and thus no health hazard to the staff performing the experiments.

- Reasonable cost, since the tests require kilogram quantities. 
- Normal boiling point between about $5{ }^{\circ} \mathrm{C}$ and $35^{\circ} \mathrm{C}$.

- Absorption of UV radiation, since the available measurement devices in the simulator are fiber-optic based UV spectrometers.

The initial search resulted in several potential compounds with reasonable $T_{b}$ and $U V$ absorption:

- $\mathrm{ClO}_{2} \quad T_{b}=11^{\circ} \mathrm{C}$

- $\mathrm{C}_{2} \mathrm{~F}_{5} \mathrm{I} \quad T_{b}=13{ }^{\circ} \mathrm{C}$

- $\mathrm{NO}_{2} \quad T_{b}=21{ }^{\circ} \mathrm{C}$

- $\mathrm{CF}_{2} \mathrm{Br}_{2} \quad T_{b}=24.6^{\circ} \mathrm{C}$

- $\mathrm{CH}_{3} \mathrm{I} \quad T_{b}=42.7^{\circ} \mathrm{C}$

The stability or toxicity of $\mathrm{ClO}_{2}, \mathrm{NO}_{2}$, and $\mathrm{CH}_{3} \mathrm{I}$ rendered them unacceptable for use in the laboratory environment. $\mathrm{C}_{2} \mathrm{~F}_{5} \mathrm{I}$ costs about $\$ 2400 / \mathrm{kg}$, and would only be used if no other compound meets the criteria. $\mathrm{CF}_{2} \mathrm{Br}_{2}$ (halon 1202) shows good promise. It is relatively inexpensive, $c a$. $\$ 200 / \mathrm{kg}$, and readily absorbs UV with peak absorbance centered near $226 \mathrm{~nm}$, well within the spectral response of the spectrometers. Although it is an ozone-depleting substance, arrangements have been made to obtain it from a stockpile, and discharge tests using $\mathrm{CF}_{2} \mathrm{Br}_{2}$ will be conducted using the NIST nacelle simulator at room temperature and $0{ }^{\circ} \mathrm{C}$. The search continues for a second suitable chemical with a lower boiling point.

\section{Suppressant Dynamics in Engine Nacelles}

Droplet Flow Around Obstacles. We have completed a series of experiments to provide data regarding the behavior of suppressant droplets as they encounter a single well-defined obstruction in their path. These results become the basis for interpreting the interactions with complex clutter and for the treatment of aerosol suppressants in the modeling, both described later in Section II.B.3.

An air stream containing the sprayed agent flowed past a cylindrical object or a body-centered cube (BCC) object representing different degrees of clutter. The cylindrical object could be at ambient temperature or heated. The properties measured were:

- The mass of fluid that struck an object and dripped into a collector pan. This fraction of the total would not have continued toward the fire zone.

- The dispersion or entrainment for those droplets that didn't stick to the object, measured using three-dimensional particle imaging velocimetry (PIV). This was summarized in the FY2002 NGP Annual Report.

- Changes in the droplet size distribution, measured using a Phase Doppler Interferometer (PDI). This involved substantial instrumentation development and is described below.

The use of three fluids enabled obtaining results as a function of boiling point and the difference between the fluid temperature and the temperature of the obstacles. The fluids were:

- Water

- $\mathrm{CH}_{3} \mathrm{OC}_{3} \mathrm{~F}_{7}$ (HFE-7000)

- $\mathrm{CH}_{3} \mathrm{OC}_{4} \mathrm{~F}_{9}$ (HFE-7100)

$$
\begin{aligned}
& \mathrm{T}_{\mathrm{b}}=100^{\circ} \mathrm{C} \\
& \mathrm{T}_{\mathrm{b}}=34^{\circ} \mathrm{C} \\
& \mathrm{T}_{\mathrm{b}}=61^{\circ} \mathrm{C}
\end{aligned}
$$


Since the previous effects were seen to depend heavily on droplet size, the current work focused on spatial and temporal resolution of droplet size and velocity distributions in the upstream and downstream vicinity of the cylinder using a PDI. In particular, the PDI was used to provide further information on droplets rebounding off the upstream face of the cylinder, vaporization of droplets near the heated cylinder, droplet sizes that are entrained into the recirculation region behind the cylinder, and the effect of agent boiling point on droplet transport. The apparatus is shown photographically and schematically in Figure 2.

The PDI creates an interference pattern (a region of alternating light and dark fringes) in the region where two laser beams intersect. This is called the probe volume or sample volume. The system used here uses the blue (wavelength $=488 \mathrm{~nm}$ ) and green (wavelength $=514.5 \mathrm{~nm}$ ) lines of an argon ion laser, separated by beam conditioning optics, and focused by the transmitting optics to intersect and form the probe volume. A droplet passing through the probe volume scatters light that exhibits an angular intensity distribution that is characteristic of the size, refractive index, and velocity of the droplet. For a droplet with known refractive index, the size and velocity can be determined by analyzing the scattered light. The PDI obtains information about the spray at a single point in space. It is also a single-particle instrument in that information is obtained for only one droplet at a time. This offers advantages over integrating techniques because the characteristics of a particular droplet (size, velocity, etc.) can be recorded and the data can be separated into classes (size classes, velocity classes) to further characterize the spray system. Analysis of a movie from a high-speed digital camera (1000 frames/s) provides information about the ensemble of droplets. The measurements were carried out at several radial ( $R$, cross-stream) positions and over a range of axial ( $Z$, streamwise) positions upstream and downstream of the cylinder. Measurements were carried out from approximately $50 \mathrm{~mm}$ upstream of the cylinder to a downstream position of $100 \mathrm{~mm}$. In the radial direction, measurements were carried out in increments of $5 \mathrm{~mm}$ from 0 to $20 \mathrm{~mm}$ in the upper hemisphere (i.e., in the positive radial direction).

The results show that:

- As the droplets approach the upstream surface of the cylinder, there is a decrease in the streamwise velocity component and an increase in the cross-stream component. Thus, little of the water $(<5 \%)$ impacted the surfaces and dripped into the collector.

- The change in the PDI laser beam intensity showed that the concentration of droplets behind the cylinder was significantly reduced from the upstream value. The recirculation zone behind the obstacle was larger for larger droplets which require a longer distance to interact with the turbulent flow field and to reduce their higher momentum.

- Many impinging droplets rebounded off of the surface and into the free stream. As expected, there was no evidence of secondary breakup of the droplets.

- For the unheated cylinder, the Sauter mean diameter $\left(\mathrm{D}_{32}\right)$ decreased in mean size on the downstream side of the cylinder (compared to the upstream side) (Figure 3a), increased in mean size with increasing radial distance from the central plane of the cylinder (Figure 4a). This amplifies the prior finding that fine droplets were preferentially entrained into the recirculation region behind the cylinder while the larger droplets impacted the cylinder surface, accumulated and dripped off, and/or rebounded and dispersed radially outward into the free stream.

- There is an increase in the droplet streamwise velocity over the cylinder for $\mathrm{R}=15$, and $20 \mathrm{~mm}$, which was also characteristic of the accelerated flow over the cylinder. 
Figure 2. View and Schematic of the Experimental Arrangement with the Laser from the Phase Doppler Interferometry System
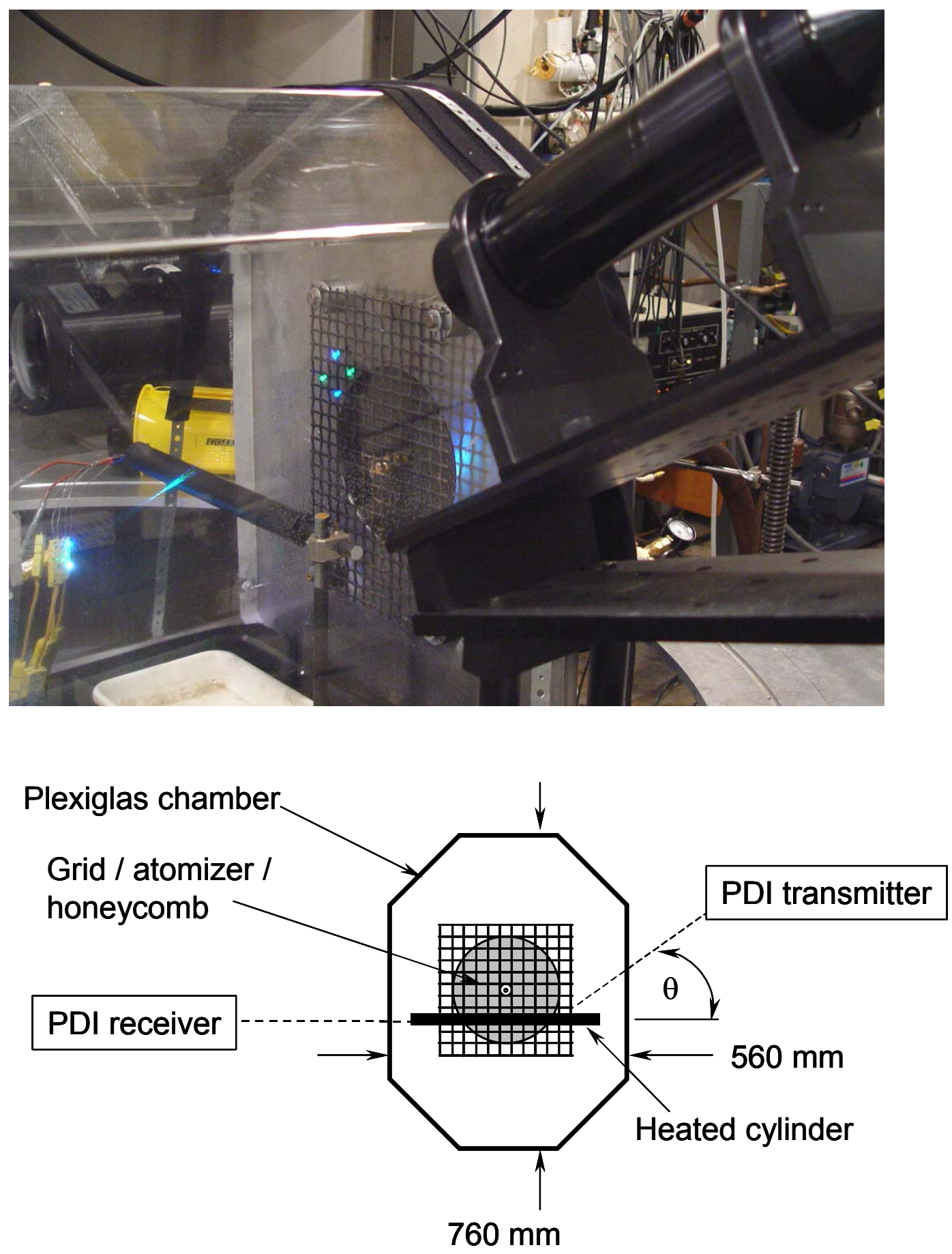

- The droplet Sauter mean diameter and both the streamwise and crossstream velocity components were consistently smaller for the heated cylinder as the droplets are transported past the cylinder surface (Figure 4a), although the changes are close to the uncertainty in the measurements. This indicates that droplet vaporization at the heated surface does not result in the complete removal of the smaller size droplets from the 
distribution, but rather decreases the size of all droplets.

- Droplet size increases and velocity decreases with increasing agent boiling point (Figure 5); the differences for the two HFEs are small but real. The HFE droplets with their lower boiling points vaporized even before reaching the obstacle surface.

Figure 3. Variation of Droplet (A) Sauter Mean Diameter and (B) Mean Streamwise Velocity with Streamwise Position at Different Cross-Stream Positions for the Unheated Cylinder. The heavy line on the abscissa represents the location of the cylinder
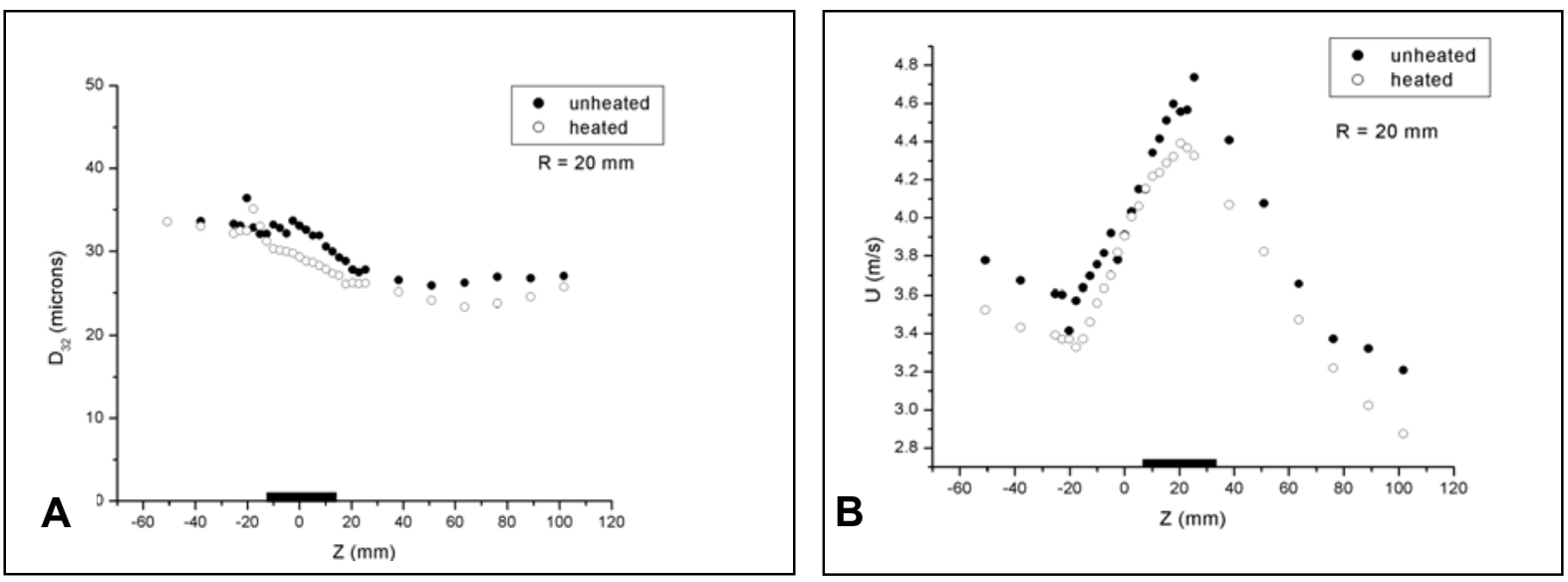

Figure 4. Variation of the Streamwise Velocity with Streamwise Position Upstream of the Unheated Cylinder at $Z=-15 \mathrm{~mm}$ and Along the Centerline.
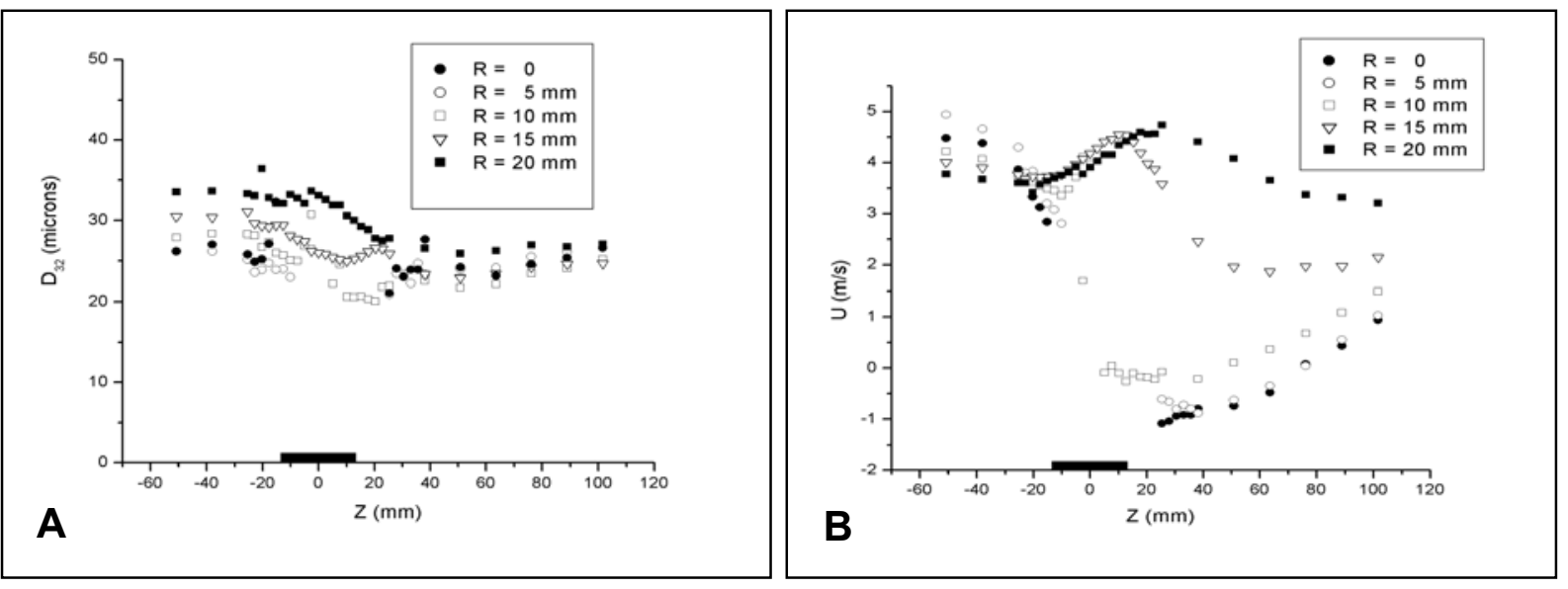
Figure 5. Comparison of the Droplet (A) Mean Size and (B) Streamwise Velocity for the Three Agents
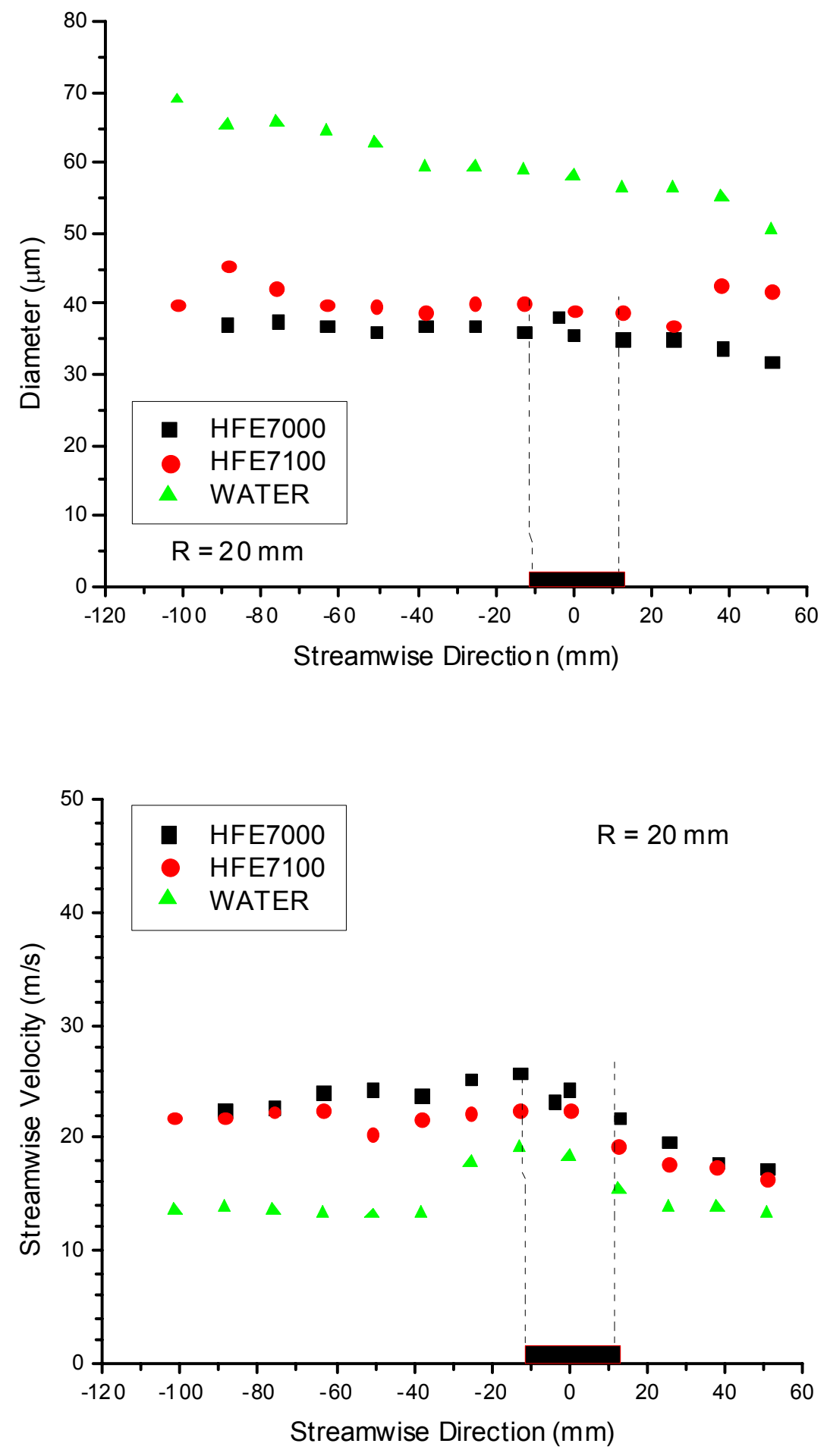
Spray-clutter interactions. A detailed characterization of the three-dimensional velocity field and the distribution of agent drop sizes downstream of generic clutter have been completed. A three-dimensional phase Doppler anemometry system allows both droplet diameter and velocity components in all three directions to be acquired simultaneously. Measurements were performed within the Suppressant Spray Flow Facility (Figure 6) with the air/water nozzle set to ca. $0.3 \mathrm{~L} / \mathrm{s}$.

\section{Figure 6. Clutter Interaction with Fine Spray in Wind Tunnel}

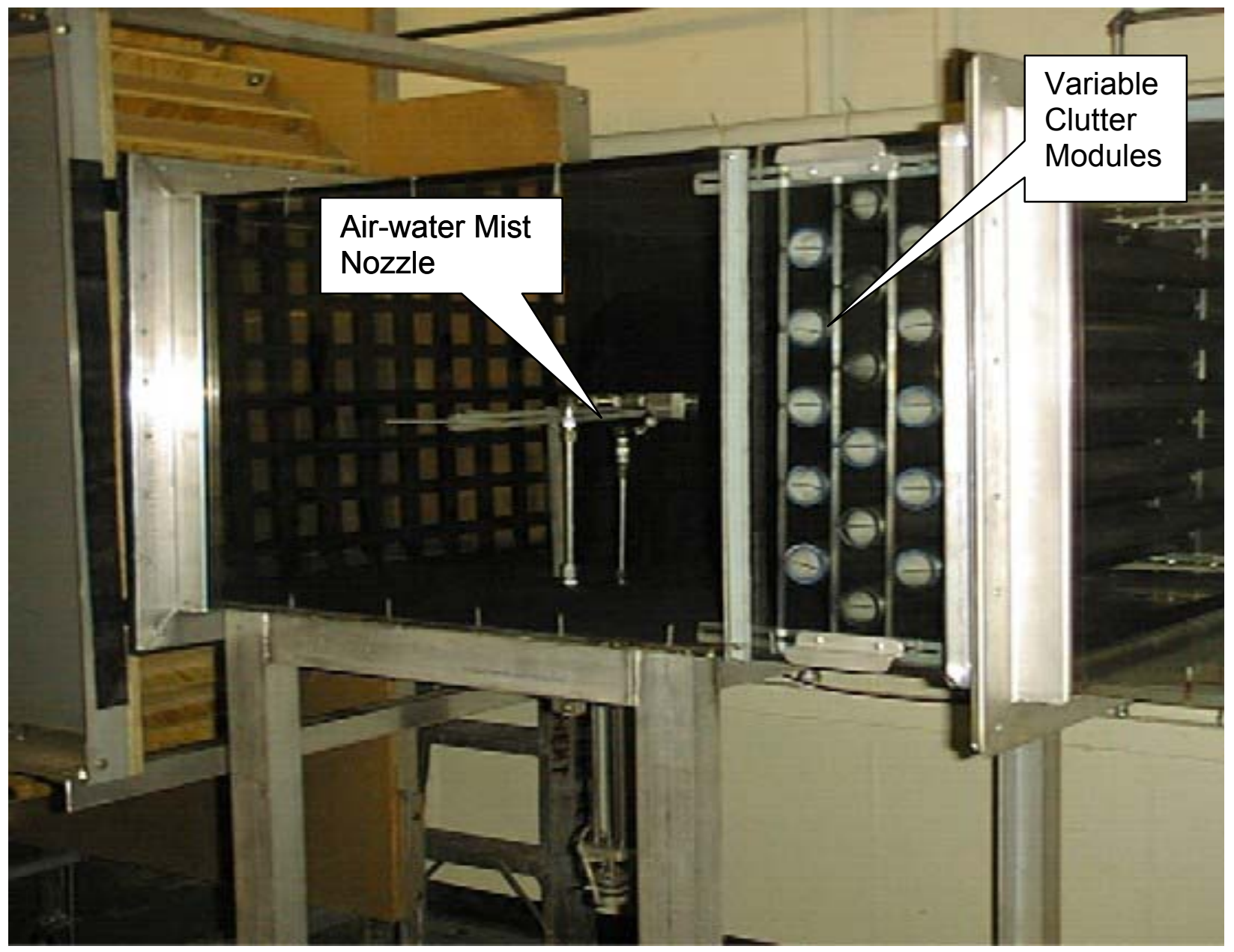

Data were acquired for three clutter spacings $(0.25 \mathrm{D}, 1 \mathrm{D}$, and $2 \mathrm{D})$ at two locations $(2 \mathrm{D}$ and $5.5 \mathrm{D})$ downstream from the trailing edge of the clutter package for three airspeeds $(1 \mathrm{~m} / \mathrm{s}, 3 \mathrm{~m} / \mathrm{s}$, and $5 \mathrm{~m} / \mathrm{s}$ ). D, the clutter rod diameter, was $5 \mathrm{~cm}$. The frequencies and length scales of turbulence upstream of the clutter were determined in order to validate the automatic data acquisition system and provide additional insight. Autocorrelation of the turbulent components derived the Prandtl mixing lengths and dimensional turbulence scales of generated eddies. Fourier spectral analyses on turbulent velocities from hot wire data and their peak frequencies determined additional modal length scales of the turbulent velocity field. These data are being organized and analyzed further for salient correlations to be used in the VULCAN modeling, and there is a coordinated team effort underway to evaluate the results from the spray-clutter 
interaction measurements using this NAVAIR nozzle.

Nacelle Simulator. The full-scale Fire and Flow Test Facility (Figure 7) is nearing completion. Next summer, we will conduct pool fire tests in it to validate the computer models further and, since it has many viewing ports, we will conduct observations of anomalous test conditions from the full-scale F/A-18 E/F ground test results.

Figure 7. 2-D Full-Scale Nacelle Test Section

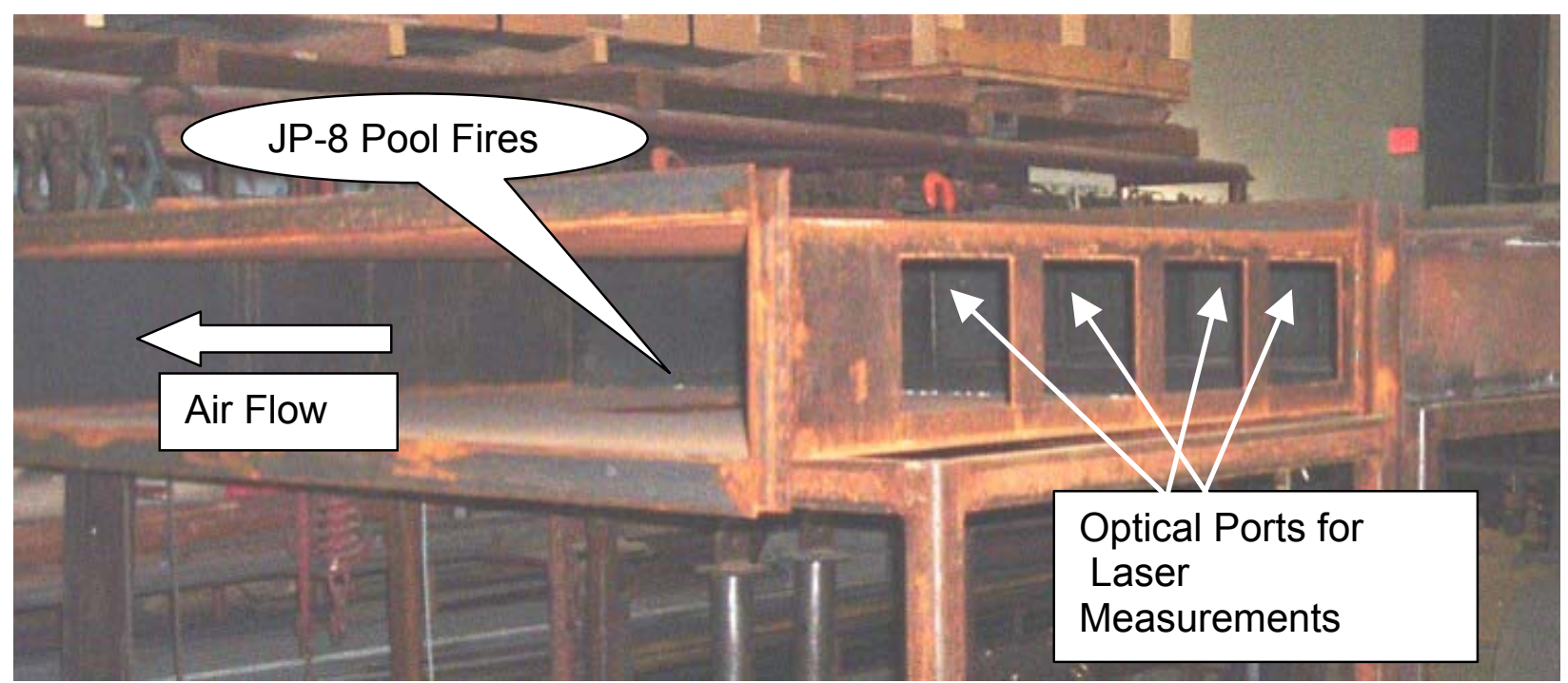

Computer Modeling of Suppressant-Clutter Interaction. We have now demonstrated that VULCAN simulations are capable of reproducing observed behavior of a gas phase suppressant with a single clutter object. The behavior is shown in Figure 8. Case A1 compares well with the experimental measurements of flames stabilized behind an obstruction in a laboratory wind tunnel (Figure 9). ${ }^{5}$

We then investigated the effect of a second clutter element on the suppression of fires stabilized behind a primary clutter object. The second element was situated to affect the flow patterns but not directly stabilize the flame. Nonetheless, the aerodynamic drag on the secondary clutter can create high and low pressure regions on the leading and trailing sides of the clutter. For highpressure regions located adjacent to flame-stabilizing recirculation zones (Figure 9, Case A5), mixing of suppressant into the stabilization region is substantially enhanced, leading to reduced suppressant requirements. Conversely, if the low-pressure region is adjacent to the flamestabilizing recirculation zones (Figure 9, Case A3), mixing of suppressant into the stabilization region is inhibited, leading to slightly greater suppressant requirements.

\footnotetext{
${ }^{5}$ F. Takahashi, W. J. Schmoll, E. A. Strader, V. M. Belovich, "Suppression Behavior of Obstruction-Stabilized Pool Flames," Combust. Sci. Tech. 163, 107-130 (2001).
} 
Figure 8. Fires Stabilized Behind a Backward-Facing Step in a Square Wind Tunnel. [The hot colors represent the flame, purple is the JP-8 pool, blue is the inlet and gray represents the structure, less the left wall and top surface that have been removed for visibility.]

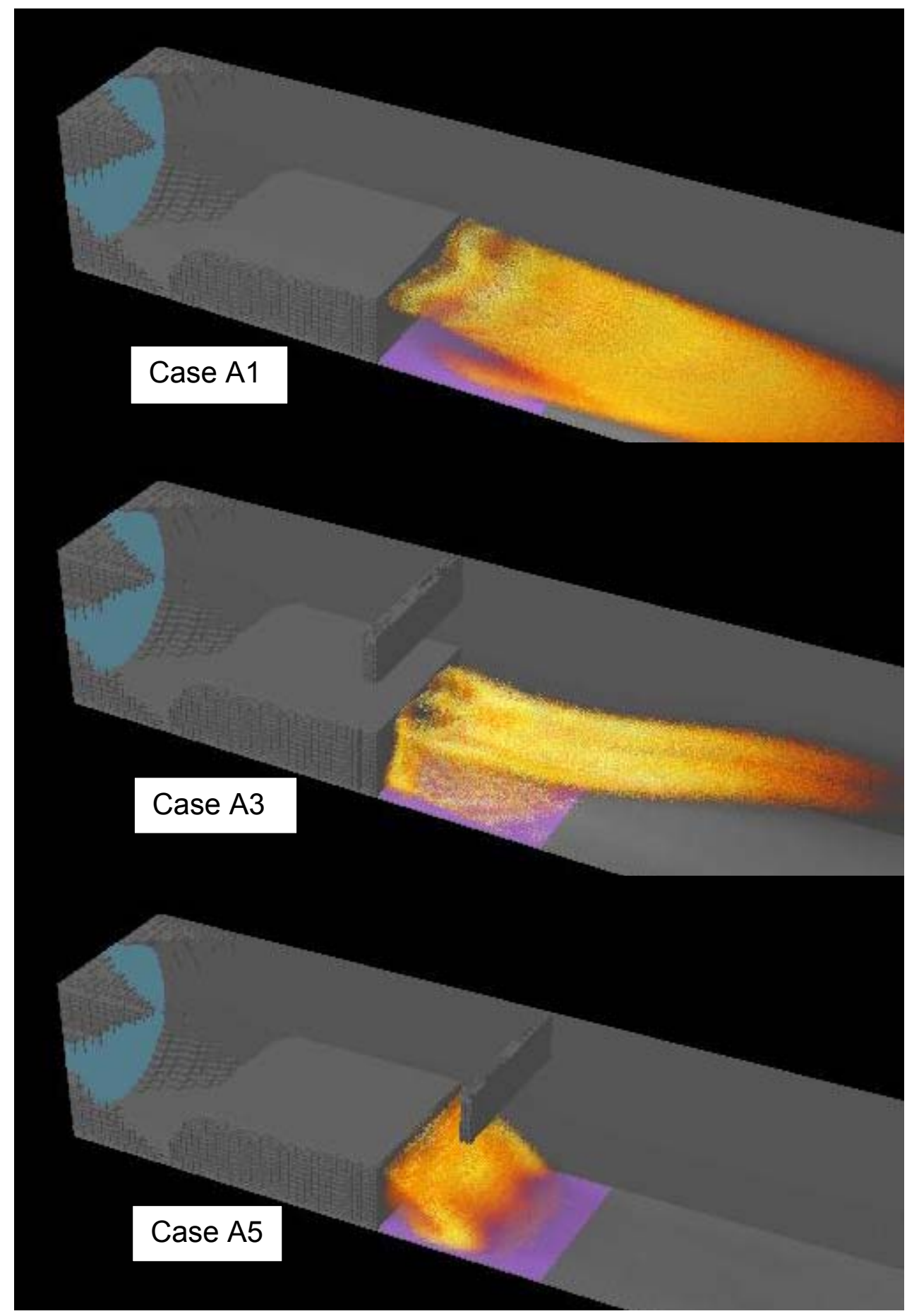


Figure 9. Comparison of Calculated and Experimental ${ }^{5}$ Suppression Times. The Correlation $^{6}$ is of the Experimental Values.

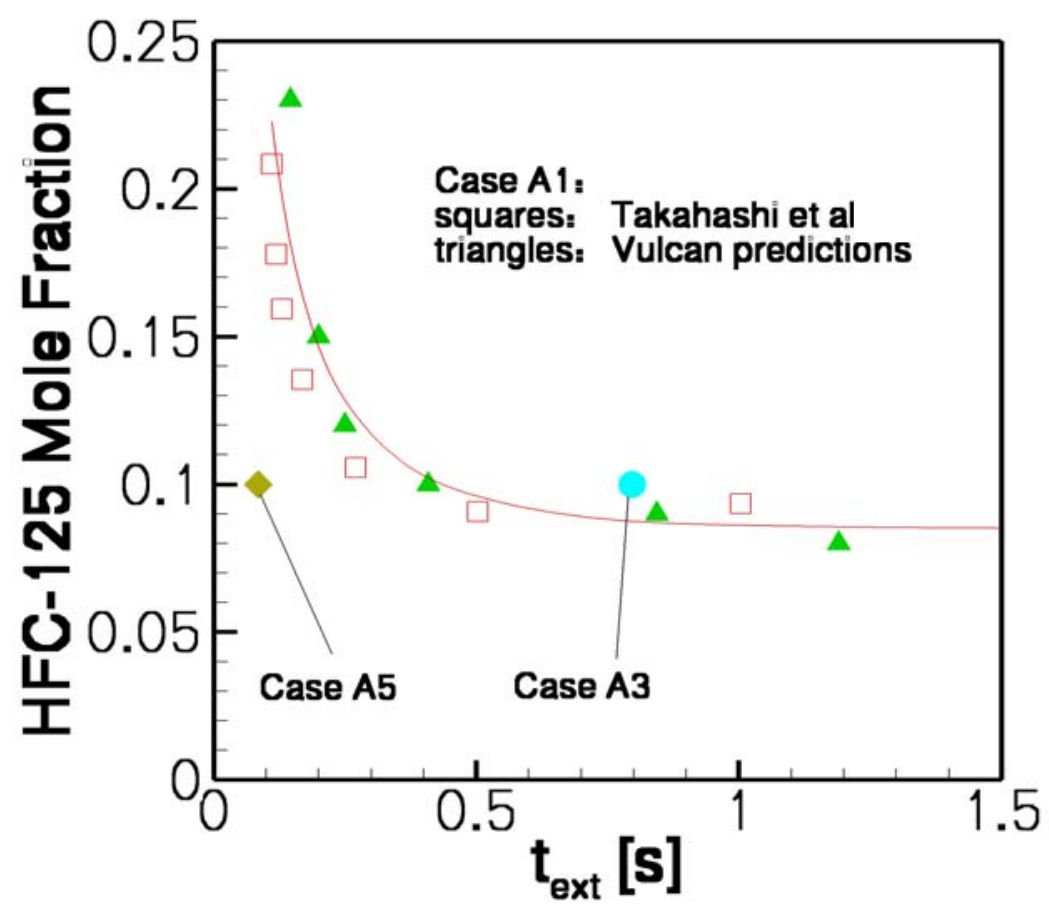

Computer Modeling of Suppression in a Prototype F-18 E/F Engine Nacelle. Simulations are being conducted using the VULCAN code in preparation for full-scale fire suppression tests using a ground-based F-18 E/F engine nacelle simulator. The objective is to identify conditions for which suppression will and will not be successful in order to test the model's capability to predict both outcomes correctly.

Pool fires have been identified as among the most difficult fires to suppress. A four-nozzle design leads to good suppressant distribution (in the absence of a fire) over the expected range of operating conditions. Figure 10 demonstrates gross fire characteristics for two such pool fires located at the forward end of the nacelle. The fire is suppressed, as indicated by the volume of hot gases going to zero very soon after the suppressant begins to be injected at $20 \mathrm{~s}$.

In order to create conditions for which fires will not be suppressed, we have capped each of the nozzles in turn. Figure 11 indicates that capping nozzle 2 has the most dramatic effect, leaving a substantial fraction of the nacelle volume with insufficient suppressant to extinguish a fire. As shown in Figure 12, the lack of suppressant is most severe along the lower nacelle regions where pool fires would exist. Interestingly, Figure 11 also indicates that capping nozzle 3 has a minimal effect on the suppressant distribution. Suppressant dispensed from nozzle 3 tends to overlap in space with the suppressant dispensed from other nozzles. Thus, the outcome of an experiment with nozzle 3 capped will be instructive.

\footnotetext{
${ }^{6}$ Hamins, A., Presser, C.; , and Melton, L., "Suppression of a Baffle-Stabilized Spray Flame by Halogenated Agents," Proc. Combust. Inst. 26, 1413-1420 (1996).
} 
Figure 10. Simulated Volume Fraction of the Nacelle for Which the Average Temperature Exceeds $700 \mathrm{~K}$ (Red Curves) and for Which the Suppressant Mass Fraction Exceeds 0.3 (Green Curves) during Fire Extinguishment for Two Flow Conditions. Solid lines: air flow $=0.33 \mathrm{~kg} / \mathrm{s}$; dashed lines: $0.66 \mathrm{~kg} / \mathrm{s}$.

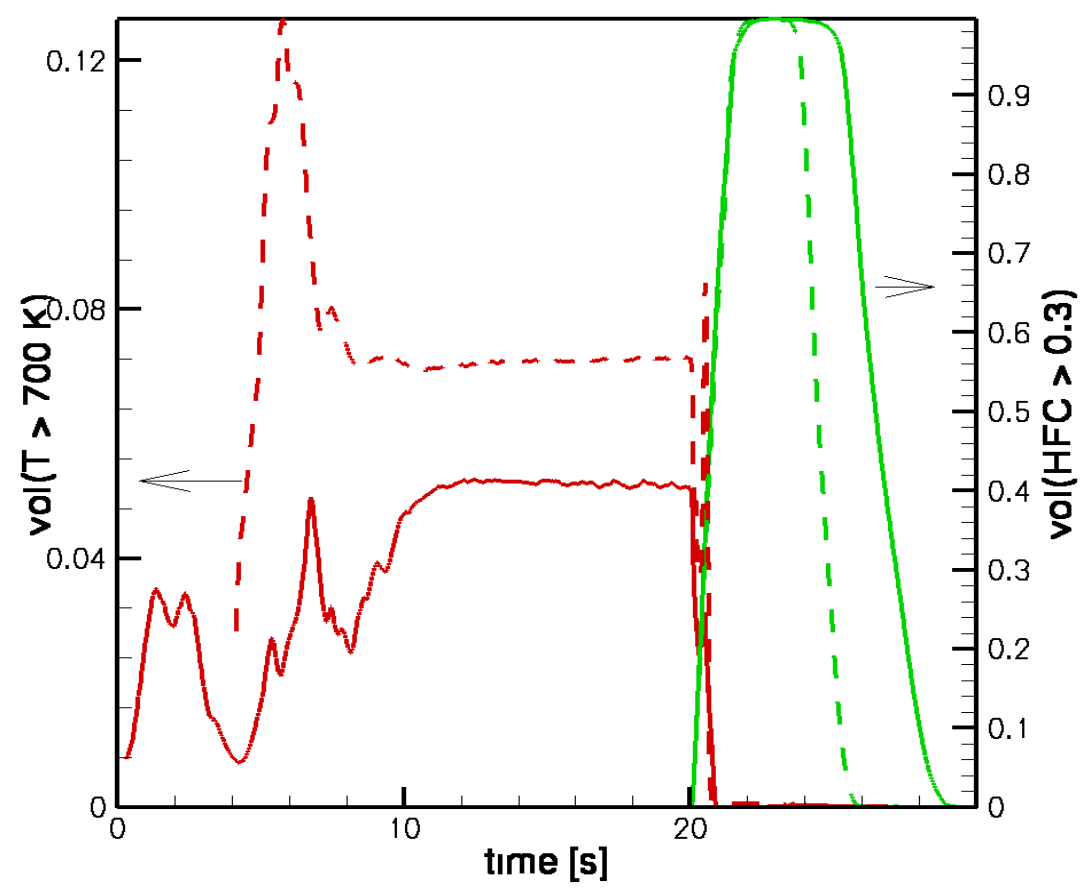

Figure 11. Effect of Removing Distribution Nozzles

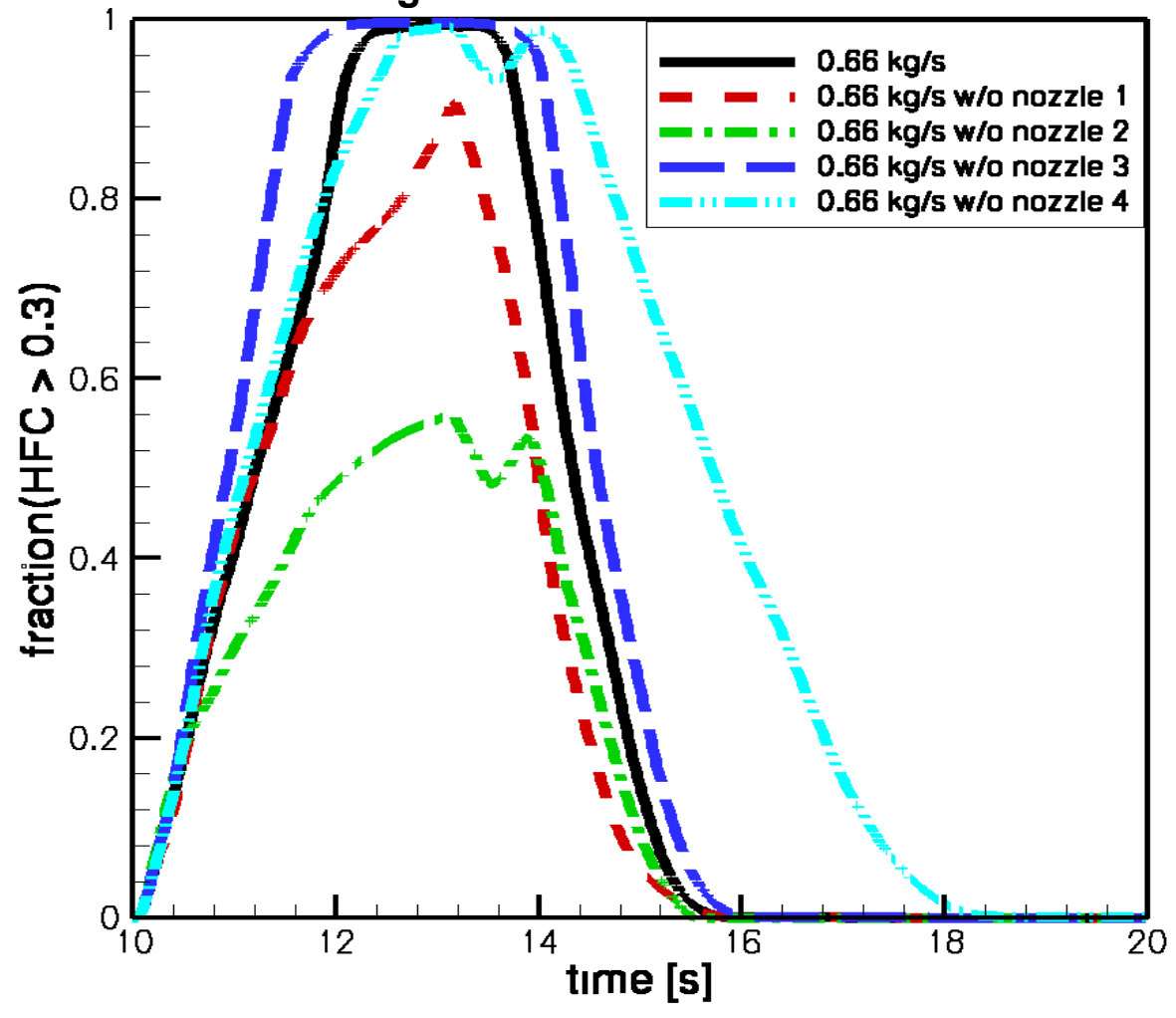


Figure 12. Simulation of HFC-125 Mass Fraction Above and Below the Engine at the Completion of Suppressant Injection with Nozzle 2 Capped. Hot Colors Indicate Insufficient Suppressant.

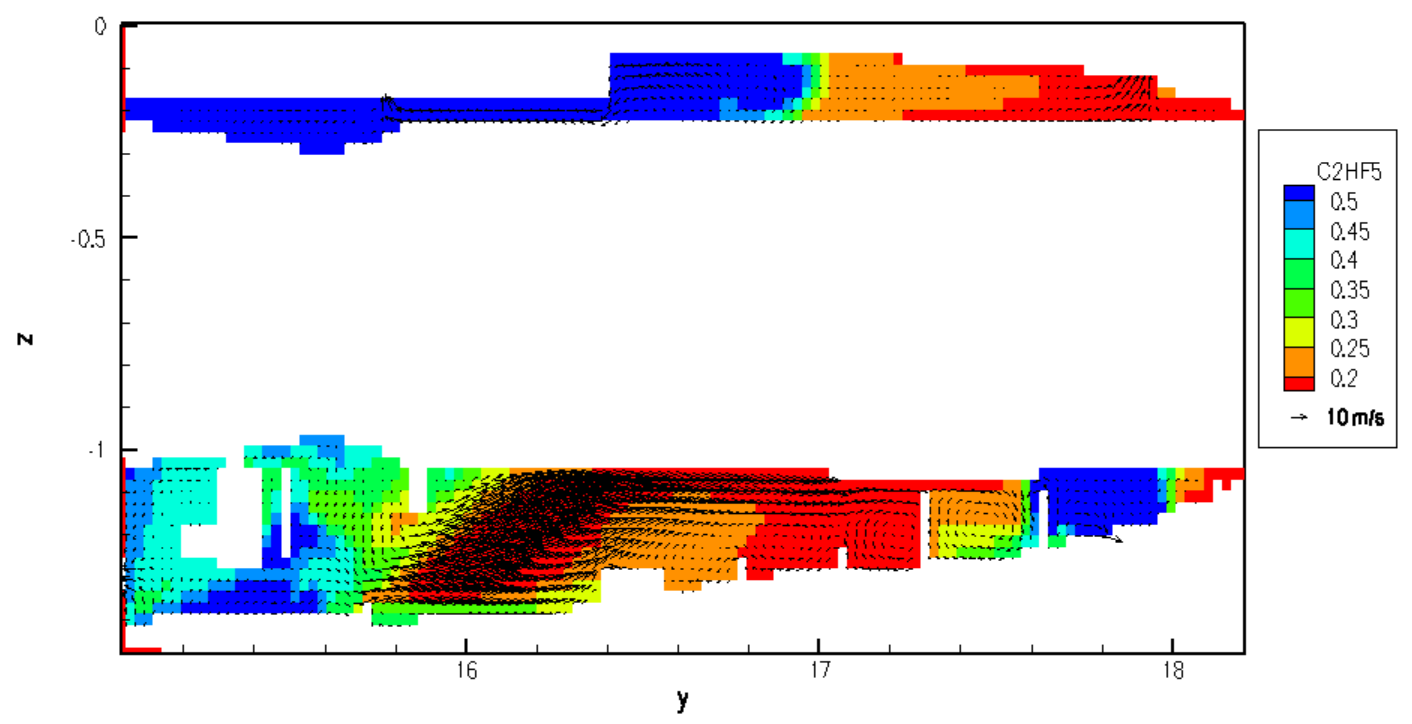

\section{Enhanced Powder Panels for Dry Bay Fire Protection}

The NGP has completed its research into enhanced powder panels with both success and high visibility. These aircraft fire protection devices, attached to flammable fluid containers adjacent to dry bays, provide passive, lightweight, effective fire protection against ballistic impact.

We first identified effectiveness issues with current commercial powder panels, developed enhanced concepts for improving powder panel performance, compared concepts through experimentation, and demonstrated performance improvements by the most promising concepts. Now, NGP researchers have optimized these concepts and verified their value through live fire testing.

Panel Optimization. Aircraft production managers have expressed concerns over such factors as panel weight, thickness, and durability. Our new designs have resulted in a $60 \%$ reduction of weight (to an areal density as low as $0.136 \mathrm{~g} / \mathrm{cm}^{2}$ ) and thickness (to as low as 1.65 $\mathrm{mm}$ ) over our prior designs. These are $30 \%$ lighter and $40 \%$ thinner than conventional commercial panels, yet they release as much as 21 times more powder mass or 42 times greater percentage of total powder. Much of this was due to an innovative overall panel design that maximizes its front face fracture relative to commercial powder panels.

We also performed an assessment of the viability of these advanced panels. The original intent was to compare an enhanced powder panel protection system with a halon fire extinguishing system. However, a side-by-side comparison turned out to be difficult. Halon fire extinguishing systems are most often employed in areas such as engine nacelles, fuel tank ullage areas, and auxiliary power units, while powder panels have only been demonstrated in dry bay areas. When halon has been used in dry bay areas, it is typically for safety-related fires and activation of a powder panel by a ballistic threat is unlikely due to the location of the dry bay. Therefore, we compared the new devices to other active dry bay fire extinguishing systems and current 
commercial powder panels. Two system weight comparisons were performed:

- A conceptual forward-fit C-130 outboard wing leading edge dry bay fire protection system. The estimated enhanced powder panel system weight was $1.2 \mathrm{~kg}$ lighter than a theoretical SPGG system and about $4.0 \mathrm{~kg}$ lighter than a commercial powder panel system.

- An existing V-22 outboard wing tip rib dry bay fire protection system. The enhanced powder panels were compared with SPGG systems and current commercial powder panels. The existing SPGG system for both V-22 outboard tip rib dry bays was estimated to be $369 \mathrm{~g}$ lighter than the enhanced powder panel system. The commercial powder panel system would be approximately $285 \mathrm{~g}$ heavier than the enhanced powder panel solution.

The results indicate that enhanced powder panels offer a justifiable option, in terms of system weight, for previously unprotected dry bays or as an alternative to areas protected by other means.

The culmination of the project was the conduct of live fire demonstration tests of the optimized enhanced powder panels. Testing involved a $0.45 \mathrm{~m}^{3}$ dry bay and fuel tank containing at least 49 liters of JP-8 fuel. Nine tests were conducted with $12.7 \mathrm{~mm}$ armor piercing incendiary projectiles fired at a velocity of approximately $757 \mathrm{~m} / \mathrm{s}$. Two tests were conducted to ensure fires could be ignited without fire protection, a test was conducted with a commercial powder panel, and six tests were conducted with enhanced powder panels. Figure 13A shows the commercial powder panel following a test that resulted in fire ignition, although the panel dislodged from the fuel tank during the impact event. Figures $13 \mathrm{~B}$ and $13 \mathrm{C}$ show two different enhanced powder panel designs. Four of the six enhanced powder panel tests resulted in prevention of fire ignition. One of the other two tests resulted in the extinguishment of a fire 0.28 second after impact; however, it was most likely caused by the ignition of a pool of residual fluid from a previous fuel tank leak. The sixth test also resulted in fire ignition, but as in the commercial panel test, the panel dislodged from the fuel tank due to an ineffective adhesive.

The tests demonstrated that enhanced powder panels as much as $26 \%$ lighter and $29 \%$ thinner than commercial powder panels could release at least four times more powder, and, in all but one test, resulted in at least three times more panel front face area removal. It was conclusive that sufficient powder was released from each of the enhanced powder panels to significantly reduce the likelihood of a dry bay fire, even using $\mathrm{Al}_{2} \mathrm{O}_{3}$, an inefficient (but inert) fire extinguishing powder. It was estimated that the enhanced panels released $40 \mathrm{~g}$ to $70 \mathrm{~g}$ of powder, compared to less than $10 \mathrm{~g}$ released by the commercial panel. Powder dispersion was evident throughout the dry bay following enhanced powder panel tests and remained dispersed for at least five minutes or more in most tests as can be seen by observing the left side of the "dry bay" in Figure $13 \mathrm{D}$.

We can thus conclude that the fire suppression performance of enhanced powder panels is:

- Far greater than their predecessors,

- Competitive with other non-halon alternatives, and

- Predictable from non-live fire tests. 
The developments initiated by this project have sparked other research and development interest, as well as interest from several aircraft programs examining fire protection alternatives.

Evaluations have also been conducted recently for integrating powder panels into the AH-64 Apache and the RAH-66 Comanche helicopters. There is potential in the Navy UH-1Y Huey and AH-1W Super Cobra legacy aircraft which are being upgraded to the AH-1Z Super Cobras and use powder panels for dry bay protection. The V-22 Osprey tiltrotor aircraft uses powder panels extensively. In addition, there is some interest for use in U.S. fixed wing aircraft that do not currently employ powder panels.

Figure 13. Photographs Following Live Fire Demonstration Tests

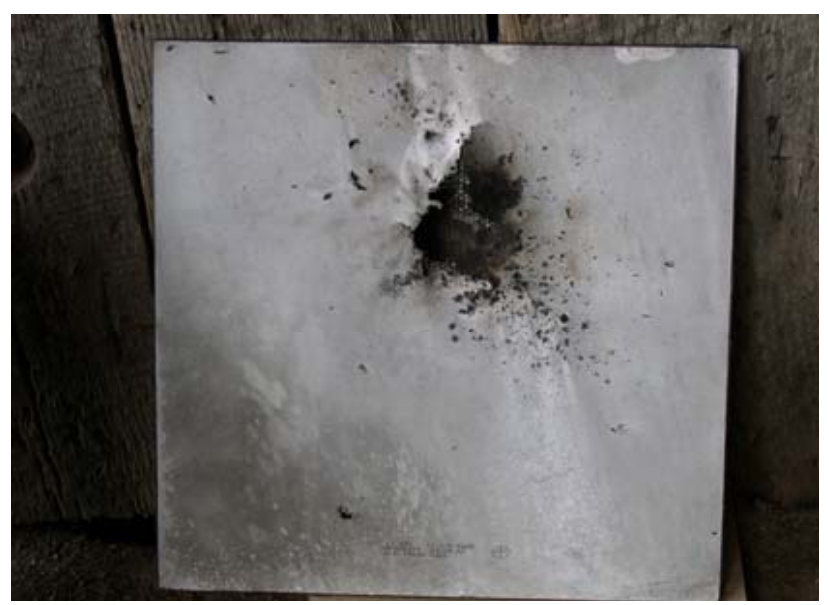

A. Commercial Powder Panel

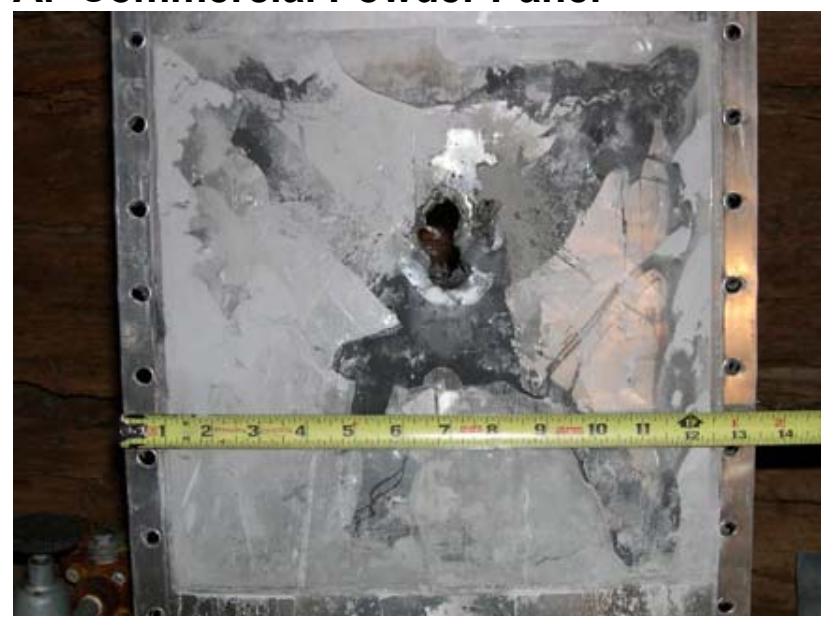

C. Enhanced Design 2

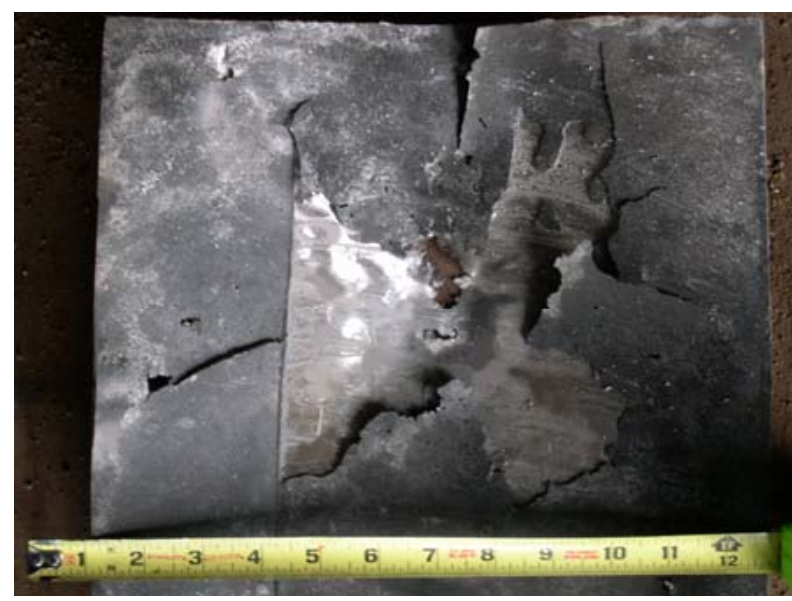

B. Enhanced Design 1

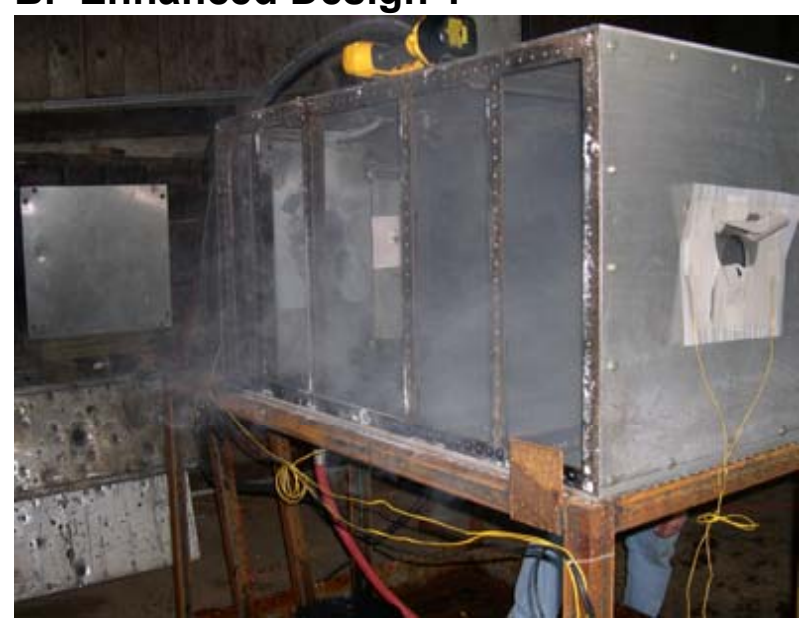

D. Enhanced Design 2 


\section{Recent Publications: Improved Suppressant Delivery}

(* indicates archival publications)

Ghee, T. and Keyser, D. "Basic Aerodynamic Shapes in a Low-Speed, Highly Turbulent Flow Field," AIAA 2003-3953, Am. Inst. Aero. Astro., Washington, DC, 2003.

Presser, C., Widmann, J.F., and Papadopoulos, G., "PIV Measurements of Droplet Transport in a Homogeneous Turbulent Flow over a Cylinder," AIAA 2003-0846, Am. Inst. Aero. Astro., Washington, DC, 2003.

Presser, C., Papadopoulos, G., and Widmann, J.F., "Droplet-Laden Homogeneous Turbulent Flow Past Unheated and Heated Cylinders," Proc. ASME/JSME Joint Fluids Engineering Conf. (FEDSM'03), FEDSM2003-45240, on CD, Am. Soc. Mech. Eng., New York, NY, 2003.

DesJardin, P.E., Presser, C., Disimile, P.J., and Tucker, J.R.., "A Phenomenological Droplet Impact Model for Lagrangian Spray Transport." AIAA 2003-1322, Am. Inst. Aero. Astro., Washington, DC, 2003.

Presser, C., Avedisian, C.T., and Johnson, B.S., "Phase Doppler Measurements of Liquid Agent Transport over a Heated Cylinder," in Gann, R.G., Burgess, S.R., and Reneke, P.A., eds., Papers from 1991-2003 Halon Options Technical Working Conferences (HOTWC), CD-ROM, NIST SP 984-1, National Institute of Standards and Technology, Gaithersburg, MD, 2003.

Disimile, P.J., Tucker, .R., Crosswell, B., and Davis, "The Transport of Water Sprays Past Generic Clutter Elements Found Within Engine Nacelles" in Gann, R.G., Burgess, S.R., and Reneke, P.A., eds., Papers from 1991-2003 Halon Options Technical Working Conferences (HOTWC), CD-ROM, NIST SP 984-1, National Institute of Standards and Technology, Gaithersburg, MD, 2003.

J. C. Hewson, S. R. Tieszen, W. D. Sundberg, P. E. Desjardin, "CFD Modeling of Fire Suppression and Its Role in Optimizing Suppressant Distribution," in Gann, R.G., Burgess, S.R., and Reneke, P.A., eds., Papers from 1991-2003 Halon Options Technical Working Conferences (HOTWC), CD-ROM, NIST SP 984-1, National Institute of Standards and Technology, Gaithersburg, MD, 2003.

Presser, C., Avedisian, C.T., and Johnson, B.S., "Phase Doppler Measurements of Liquid Fire Suppressants over a Heated Cylinder," AIAA 2004-0479, Am. Inst. Aero. Astro., Washington, DC, accepted for 2004.

*Yang, J.C., Manzello, S.L., Nyden, M.R., Connaghan, M.D., "Cold Discharge of $\mathrm{CF}_{3} \mathrm{I}$ in a Simulated Aircraft Engine Nacelle," Fire Safety Science - Proc. of the Seventh International Symposium, 715-728, (2003).

Cyphers, D.C., Frederick, S.A., and Haas, J.P., "Demonstrating Enhanced Powder Panels," in Gann, R.G., Burgess, S.R., and Reneke, P.A., eds., Papers from 1991-2003 Halon Options Technical Working Conferences (HOTWC), CD-ROM, NIST SP 984-1, National Institute of Standards and Technology, Gaithersburg, MD, 2003.

Haas, J.P., Cyphers, D.C., and Frederick, S.A., "Enhanced Powder Panel Concepts," Twenty Seventh Annual American Institute of Aeronautics and Astronautics Dayton-Cincinnati Aerospace Science Symposium, Dayton, OH, March 5, 2002. 
Cyphers, D.C., "Enhanced Powder Panels - Applying New Ideas to an Old Fire Extinguishing Method," Military Fire Protection Systems Edition, FS-World.com Magazine, accepted for publication.

\section{VIABILITY OF NEW SUPPRESSANT TECHNOLOGIES}

During the coming year, we will plan and begin conduct of a series of real-scale engine nacelle fire suppression tests. Their purpose will be to verify the fire suppression principles developed in the NGP by comparing the outcome of the tests with predictions based on NGP-developed technology and to identify any as-yet unexplained suppression phenomena.

The first step in this process is to develop a set of "Lessons Learned" from each of the NGP projects. These include findings of both research and operational value. This compilation is nearly complete. The second step, to be completed this winter, will be to extract broader principles that underlie fire suppression science and practice. 


\section{INDEPENDENT PROGRAM ASSESSMENT}

The NGP Independent Review Panel (IRP) was again asked to assess progress to date and to recommend actions that could enhance the prospects for NGP research to result in viable and practical alternative fire suppression technologies with NGP resources remaining at or near currently projected levels.

The IRP was impressed by the thoughtful way their 2001 recommendations have been addressed and by the tightened focus of the program. They further observed:

1. They are confident that valuable design products will be delivered by this program.

2. The new 2003 start to integrate and draw inferences from the results of the technically disparate studies is important and to be commended. A fully integrated effort to understand how each piece can be fitted into the whole will make the results much more valuable than the sum of the parts.

3. The proposed new 2003 start to better understand the low-temperature fire history and requirements is also to be commended. Determining how the compartment lowtemperature operating limits, the ignition probability at low temperatures, and the fire histories at low temperatures combine to define the risk associated with low-temperature operation is also likely to open the design space and provide a wider range of options than would be achieved by simply using the worst-case combination of operating temperatures.

The IRP had one new recommendation: Within the existing NGP budget and schedule constraints, evaluate the effects of discharges of $\mathrm{CF}_{3} \mathrm{I}$ in aircraft fire protection systems, as opposed to fuel tank inerting systems, on stratospheric ozone depletion and establish a methodology applicable for this purpose to other candidate agents containing bromine or iodine. The F-16 fuel tank inerting study using $\mathrm{CF}_{3} \mathrm{I}$ could easily be inappropriately interpreted to deny use of $\mathrm{CF}_{3} \mathrm{I}$ and similar chemicals in any application.

\section{WHAT LIES AHEAD?}

As the NGP approaches the meeting of its goal, the research will be focusing on two technical components:

- Evaluating the "world of chemistry" for new flame suppression chemicals that are operable in aircraft dry bays and engine nacelles. It is essential that as many candidates as possible are identified and screened as potential halon 1301 alternatives. It is equally important that chemical families with no potential be so designated, along with the reasons for the designation. Thus, for other applications or should suppressant requirements change for fire suppression in aircraft, future investigators will have the benefit of the current program findings.

- Developing principles for optimizing suppressant storage and delivery. Both research and engineering experimentation have shown that there is much system effectiveness to be gained if the suppressant is deployed efficiently and much to be lost for a delivery design that is incompatible with the suppressant properties. 
As these efforts near completion, a modest series of real-scale fire suppression tests will be conducted with the purpose of demonstrating the validity of the above findings.

The prognosis for successfully meeting the revised NGP goal is excellent, given the technical infrastructure and cadre of experts advanced by the NGP. The Department of Defense has already made use of NGP technology in testing, selecting, and designing suppression technologies for some Military Service aircraft. More such test series are being planned and presumably will become the norm for the remaining platforms. 


\section{APPENDIX A. NGP PROJECTS}

The system for the identifier codes for the projects was developed at the beginning of the NGP and follows the now outdated program structure in the original NGP Strategy Document, which is available at the NGP web site. For current use, the important information is located following the second slash (e.g., 3A/1/789). In this example, the project was funded in fiscal years 1997, 1998 , and 1999.

\section{A. SUPPRESSANT SCREENING TESTS}

3A/1/789. DISPERSED LIQUID AGENT FIRE SUPPRESSION SCREEN; Principal Investigator: Jiann C. Yang, NIST

3A/2/890. TRANSIENT-APPLICATION-RECIRCULATING-POOL-FIRE AGENT EFFECTIVENESS SCREEN; Principal Investigator: William Grosshandler, NIST

3B/1/89. TOXICOLOGICAL ASSESSMENT OF HUMAN HEALTH CONSEQUENCES ASSOCIATED WITH INHALATION OF HALON REPLACEMENT CHEMICALS; Principal Investigator: Darol Dodd, AFRL

3B/2/8. AGENT COMPATIBILITY WITH PEOPLE, MATERIALS AND THE ENVIRONMENT; Principal Investigators: Marc Nyden, NIST, and Stephanie Skaggs, Universal Technical Services

\section{B. NEW FLAME SUPPRESSION CHEMISTRY}

2A/1/7890, /2/890. MECHANISMS OF ULTRA-HIGH EFFICIENCY CHEMICAL SUPPRESSANTS; Principal Investigators: James Fleming, NRL, and Kevin McNesby, ARL

4D/2/7. IDENTIFICATION AND PROOF TESTING OF NEW TOTAL FLOODING AGENTS; Principal Investigator: Robert E. Tapscott, NMERI; COR: Andrzej Miziolek, ARL

4B/1/8,4D/15/01. TROPODEGRADABLE BROMOCARBON EXTINGUISHANTS; Principal Investigator: J. Douglas Mather, NMERI; COR: Ronald Sheinson, NRL

4B/2/8,4D/3/7. FLAME INHIBITION BY PHOSPHORUS-CONTAINING COMPOUNDS; Principal Investigator: Elizabeth M. Fisher, Cornell University; COR: Andrzej Miziolek, ARL

4D/14/1. FLUOROALKYL PHOSPHOROUS COMPOUNDS; Principal Investigator: Douglas Mather, NMERI

4C/1/890. SUPER-EFFECTIVE THERMAL SUPPRESSANTS; Principal Investigator: William Pitts, NIST

4D/13/1. EFFECTIVE, NON-TOXIC METALLIC FIRE SUPPRESSANTS; Principal Investigator: Gregory Linteris, NIST 
4B/3/8901. ENVIRONMENTAL IMPACT OF NEW CHEMICAL AGENTS FOR FIRE SUPPRESSION; Principal Investigators: Robert Huie and Marc Nyden, NIST; Andrzej Miziolek, ARL

4B/4/0123. LOW TEMPERATURE PERFORMANCE OF HIGH BOILING POINT SUPPRESSANTS; Principal Investigator: Jiann Yang, NIST

4B/5/0123. ALTERNATIVE SUPPRESSANT CHEMICALS; Principal Investigator: Richard Gann, NIST

4B/6/23 ENVIRONMENTALLY ACCEPTABLE SUPPRESSANTS; Principal Investigator: Douglas Mather, Chemical Development Systems; Scientific Officer: Richard Gann, NIST

\section{NEW AND IMPROVED AEROSOL SUPPRESSANTS}

2B/1/78901. SUPPRESSION EFFECTIVENESS OF AEROSOLS AND PARTICLES;

Principal Investigator: Ronald Sheinson, NRL

2B/2/89. DROPLET INTERACTIONS WITH HOT SURFACES; Principal Investigator: Yudaya Sivathanu, En'Urga, Inc.; COR: William Grosshandler, NIST

2B/3/89. TECHNICAL SUPPORT FOR THE STUDY OF DROPLET INTERACTIONS WITH HOT SURFACES; Principal Investigator: Jiann Yang, NIST

4A/1/890. POWDER-MATRIX SYSTEMS; Principal Investigator: Gregory Linteris, NIST

4D/1/7. ELECTRICALLY CHARGED WATER MISTS FOR EXTINGUISHING FIRES; Principal Investigator: Charles H. Berman, Titan Corp.; COR: Ronald Sheinson, NRL

4D/4/7. DEVELOPMENT OF A SELF ATOMIZING FORM OF WATER; Principal Investigator: Richard K. Lyon, EER, Inc.; COR: William Grosshandler, NIST

4D/7/8. DENDRITIC POLYMERS AS FIRE SUPPRESSANTS; Principal Investigator: Nora Beck Tan, ARL

\section{IMPROVED SUPPRESSANT DELIVERY}

2C/1/789. STABILIZATION OF FLAMES; Principal Investigator: Vincent Belovich, AFRL

4D/6/8. DUAL AGENT APPROACH TO CREW COMPARTMENT EXPLOSION SUPPRESSION; Principal Investigator: Douglas Dierdorf, ARA Corp.; COR: Andrzej Miziolek, ARL

4D/17/0. A METHOD FOR EXTINGUISHING ENGINE NACELLE FIRES BY USE OF INTUMESCENT COATINGS; Principal Investigator: Leonard Truett, Eglin AFB

5A/1/012. PARAMETRIC INVESTIGATION OF DROPLET ATOMIZATION AND DISPERSION OF LIQUID FIRE SUPPRESSANTS; Principal Investigator: Cary Presser, NIST 
5D/1/9013. ADVANCED PROPELLANT/ADDITIVE DEVELOPMENT FOR GAS GENERATORS; Principal Investigators: Gary Holland, Aerojet, and Russell Reed, NAWC-WPNS; COR: Richard Gann, NIST

5E/1/12. ENHANCED POWDER PANELS; Principal Investigator: Dan Cyphers, Skyward, Ltd.; COR: Martin Lentz, Eglin AFB

6A/1/0123. FIRE SUPPRESSANT DYNAMICS IN CLUTTERED WEAPONS SYSTEM COMPARTMENTS; Principal Investigator: David Keyser, NAVAIR

6B/1/89. SUPPRESSANT FLOW THROUGH PIPING; Principal Investigator: John Chen, Lehigh University; COR: William Grosshandler, NIST

6C/1/1. MECHANISM OF UNWANTED ACCELERATED BURNING; Principal Investigator: Anthony Hamins, NIST

\section{E. VIABILITY OF NEW SUPPRESSANT TECHNOLOGIES}

1A/1/78. DEVELOPMENT OF MODEL FIRES FOR FIRE SUPPRESSION RESEARCH; Principal Investigator: Anthony Finnerty, ARL; Associate Investigators: James Tucker, AFRL and Juan Vitali, ARA; Ronald Sheinson, NRL

1C/1/8901. RELATIVE BENEFIT ASSESSMENT OF FIRE PROTECTION SYSTEM CHANGES; Principal Investigator: Michael Bennett, Eglin AFB

3C/1/789. LASER-BASED INSTRUMENTATION FOR REAL-TIME, IN-SITU MEASUREMENTS OF COMBUSTIBLE GASES, COMBUSTION BYPRODUCTS, AND SUPPRESSANT CONCENTRATIONS; Principal Investigator: Kevin McNesby, ARL

3C/2/890. FAST RESPONSE SPECIES CHARACTERIZATION DURING FLAME SUPPRESSION; Principal Investigator: George Mulholland, NIST

6E/1/3. VERIFICATION OF SUPPRESSION PRINCIPLES; Principal Investigator: Michael Bennett, Bennettech; COR: Martin Lentz, Eglin AFB

\section{F. FUEL TANK INERTION}

5C/1/9. ACTIVE SUPPRESSION FOR FUEL TANK EXPLOSIONS; Principal Investigator: Leonard Truett, Eglin AFB 


\title{
APPENDIX B. REPORT OF THE INDEPENDENT REVIEW PANEL
}

\section{REPORT OF THE INDEPENDENT REVIEW PANEL}

\author{
ON THE
}

\section{NEXT GENERATION FIRE SUPPRESSION TECHNOLOGY PROGRAM (NGP)}

January 30, 2003

Documenting the November 2002 Review

Thor I. Eklund, Ph.D.

Eklund Consulting Services

Phillip R. Westmoreland, Ph.D.

Professor -Department of Chemical Engineering

University of Massachusetts Amherst

Glenn Harper - Chair

Technical Fellow

Boeing - Phantom Works 


\section{The 2002 Independent Review Panel Report}

\section{on the \\ Next Generation Fire Suppression Technology Program (NGP)}

\section{Summary:}

The 2002 Independent Review Panel (IRP) met November 13, 2002, coincident with the 2002 Annual Research Meeting (ARM) of NGP participants.

The IRP is impressed by the thoughtful way the 2001 recommendations have been addressed and by the tightened focus of the program. Several tasks have been completed, some are still in work and a few new tasks are about to be started. The following general observations are presented:

Observations (No action recommended):

1) We are confident that valuable design products will be delivered by this program.

2) The decision not to be restrained by retrofit issues will open up the study space and is likely to result better products for new aircraft designs.

3) The proposed new 2003 start to integrate and draw inferences from the results of the disparate studies is important and to be commended. A fully integrated effort to understand how each piece can be fitted into the whole will make the results much more valuable than the sum of the parts.

4) The proposed new 2003 start to better understand the low-temperature fire history and requirements is also to be commended. Determining how the compartment lowtemperature operating limits, the ignition probability at low temperatures, and the fire histories at low temperatures combine to define the risk associated with low-temperature operation is also likely to open the design space and provide a wider range of options than would be achieved by simply using the worst-case combination of operating temperatures.

The IRP noted nothing that would change its conclusions and recommendations from the 2001 IRP report; thus, the recommendations of that report still apply with the recognition that all the recommendations have been or are being thoughtfully addressed.

There is one new general recommendation:

1) Within the existing NGP budget and schedule constraints, evaluate the effects of discharges of $\mathrm{CF}_{3} \mathrm{I}$ in aircraft fire protection systems, as opposed to fuel tank inerting systems, on stratospheric ozone depletion and establish a methodology applicable for this purpose to other candidate agents containing bromine or iodine. The F-16 fuel tank inerting study using $\mathrm{CF}_{3} \mathrm{I}$, which is discussed in the following section, could easily be inappropriately interpreted to deny use of $\mathrm{CF}_{3} \mathrm{I}$ and similar chemicals in any application. It is important to insure that science, not the inappropriate application of some report's conclusion, is used to allow or deny use of promising fire protection chemicals. 


\section{Background:}

The Next Generation Fire Suppression Technology Program (NGP) is sponsored by the Department of Defense (DOD) Strategic Environmental Research and Development Program (SERDP) and managed through the National Institute of Standards and Technology (NIST). The currently stated goal is to "develop and demonstrate technology for economically feasible, environmentally acceptable and user-safe processes, techniques, and technologies that meet the operational requirements currently satisfied by Halon 1301 in aircraft." In December 2001, a SERDP-recommended Independent Review Panel (IRP) was convened by the NGP Program Manager. Along with assessing the technical soundness of the NGP, the IRP was tasked with recommending actions that could enhance prospects for success in the program within anticipated funding levels and remaining timeframe.

In evaluating the work done to that time and the individual projects underway, the IRP reached very favorable conclusions on the productivity, utility, and technical quality of research done within the NGP. The NGP research findings are particularly valuable to the extent that they are based on fundamental findings on physical and chemical mechanisms associated with fire suppression phenomena. As such, the findings should support generalization so that trends and behaviors could be used to optimize extinguishing system designs and to isolate primary factors associated with troublesome issues such as reignition after agent delivery. The IRP developed recommendations with a focus being on ensuring that the technical products of the NGP be transferable to and useful for future aircraft fire extinguishing applications. This report should be considered an extension of the IRP report issued February 2002 with the comments and recommendations of that report still applicable, recognizing that those recommendations have been, or are being, thoughtfully addressed.

The NGP Program Manager invited the IRP to reconvene for an additional review coincident with the November 2002 Annual Research Meeting (ARM) of NGP participants. This afforded the IRP the opportunity to:

1) Reevaluate its prior-year conclusions and recommendations,

2) Ascertain the impact of the IRP recommendations on the present and planned NGP,

3) Evaluate the present direction and scope of the NGP, and

4) Revise previous or document new conclusions and recommendations in the context of resource availability and technical influences emanating from outside the NGP.

In this 2002 review, the IRP focus remains fixed on the goal of maximum utility for application in future aircraft fire-protection systems.

\section{External Developments:}

In the worldwide efforts to find alternatives to the halons for aviation applications, the past year has yielded continued incremental progress in the spectrum on fire protection installations, devices, and techniques. For the first time there are now available approved hand extinguishers that, though heavier, are equivalent to Halon 1211 bottles for civil aviation applications. Halon alternatives are also now available to protect the lavatories on commercial aircraft. The FAA has completed establishing Minimum Performance Standards (MPS) for halon alternatives for most of the systems falling under its purview and is in the testing phase of MPS for engine nacelle certification requirements. It is recognized that promulgating an MPS provides the basis for 
accepting a proposed Halon replacement but does not itself provide or identify specific alternative agents. Substantial new developments and demonstrations have been made using membrane technology for generating nitrogen-enriched air (NEA) not only for fuel tank inerting but also for potential in use for fire protection in aircraft unoccupied compartments.

In rescue and firefighting, USAF testing has demonstrated an improved co-flowing potassium bicarbonate and AFFF combination that offers a firefighting capability for large two-dimensional and three-dimensional fuel fires with effectiveness such that Halon 1211 would not be needed as a complementary firefighting agent. The general trend in successful halon replacement in the aviation arena has been application-specific. Rather than finding specific compounds that can be used in lieu of one or another of the halons, the trend has been to establish the level of protection needed in a specific application, then to develop an alternate "Agent" or new technology or approach to provide protection in that application.

The May 2002 annual meeting of the Halon Options Technical Working Group (HOTWC) was for the first time was managed by the NGP, and future meetings will continue to be the responsibility of the NGP. Had it not been for the NGP support, this vital vehicle for Halon alternatives research would have ceased operations. The annual meeting has proven important for a host of different reasons, including the technical interchange of the NGP research community with the extinguishing system manufacturers and foreign researchers. The annual HOTWC meeting represents a valuable platform connection all the major communities involved in Halon Replacement. Continued NGP involvement in this activity is encouraged.

In terms of impact on the NGP and the use of $\mathrm{CF}_{3} \mathrm{I}$, one of the most significant development was a report issued by an independent review panel assessing critical technical issues relating to implementation of $\mathrm{CF}_{3} \mathrm{I}$ as a replacement for Halon 1301 in F-16 wing tank inerting. This report was sponsored by the Director of Defense Research and Engineering (DDR\&E) and is titled "Suitability of $\mathrm{CF}_{3} I$ to Replace Halon 1301 as the Inerting Agent in Wing Fuel Tanks on the F16 Aircraft". The report claims that $\mathrm{CF}_{3} \mathrm{I}$ 's stratospheric ozone depletion as compared to Halon 1301 falls between one-eighth and one and two-thirds as damaging. While the subject F-16 wing tank inerting application is not one that is being addressed in the NGP effort, this new report has potentially far-reaching policy ramifications in terms of impact on acceptability of some $\mathrm{h}$

Halon replacements studied in the NGP. In as much as its limited resources allow, the IRP believes it important that the NGP formally assess the impact of the DDR\&E conclusions on both past and future NGP work and document any resultant changes in conclusions, recommendations, and program direction. It would be unfortunate if the conclusions of this study were to be improperly applied to cancel research in an otherwise attractive technology.

\section{ARM Highlights:}

The ARM presentations covered twelve projects including two new starts for FY2003. Four of these project presentations stood out to the IRP - two $(5 \mathrm{E} / 1$ and $6 \mathrm{C} / 1)$ for strong progress evidenced since the preceding $2001 \mathrm{ARM}$ and two (5D/1/901 and 5A/1/01) for their continued very strong multiyear progress and clear potential usefulness in replacing Halon 1301 for aviation applications.

1) The powder panel research (5E/1) has apparently generated great interest in both the military aircraft vulnerability arena (specifically JTCG/AS) and the civilian aircraft catastrophic failure prevention program (FAA). Both test programs evaluated the 
Skyward research panels with extremely positive results. The subject applications (military aircraft dry bays and civil aircraft fuel lines exposed to projectiles from failed engines) have not traditionally been protected by Halon 1301 systems. However, the successful performance of the powder panels have provided a level of interest that may well result in a near-term deployed powder panel product in specific applications.

Recommendation: This program's success appears to be largely dependent on the innovative approach to design of the "front panel" which allows a much larger fraction of the powder to be released at impact. The new design for these panels needs to be carefully reviewed and tested to insure that the shock, vibration, acceleration (etc.) environment of these panels will not cause the powder to "settle" and defeat the system. One of the reasons for selection of the older design was to address these issues.

2) The project on Mechanisms of Unwanted Accelerated Burning (6C/1) successfully identified and analyzed salient tests from a variety of sources over the past year and was able to provide a credible rationale for the causes and deleterious effects of unwanted accelerated burning during discharge of extinguishing agents. The valuable research reported here indicates that attempting to optimize agent quantities to minimize system weight could inadvertently expose the protected system to destructive pressure rise during the extinguishing process.

The IRP believes these results have particular relevance to the extraction of design heuristics for suppression systems in order to avoid designs with marginal performance.

3) Research on solid propellant fire extinguishers and hybrid fire extinguishers $(4 \mathrm{~B} / 4 / 01)$ continued to show excellent potential for various solid gas generator devices to replace Halon 1301 systems in aircraft powerplant applications. Effective fire extinguishing was shown by means of propellant-generated aerosol alone and by hybrid devices using propellant-generated aerosol in combination with water-based salt or higher-boiling fluorocarbon agents. Hybrid tests with $\mathrm{CF}_{3} \mathrm{I}$ were particularly promising and showed no adverse cold-temperature effects.

Recommendation: The hybrid designs utilizing pyrotechnic charges to expel liquid or gaseous agents are also promising in that they appear to reduce the sensitivity of discharge pressure to "agent temperature" which can sometimes degrade performance at extreme temperatures. The potential negative impact of false discharge and material compatibility issues due to use of propellant-generated aerosols also need to be carefully considered.

4) The experimental investigation of droplet atomization and dispersion (4B/4/01) appears to be on the threshold of gathering extremely important data on droplet dynamics in the vicinity of heated and unheated cylinders. In addition to water, the test liquids are slated to be HFE7000 and HFE7100.

In addition to providing data sets for incorporation into the VULCAN fire code, the analysis of this data can be expected to provide valuable heuristics in terms of agent behavior in the vicinity of engine nacelle clutter. The heuristics also should also include information on design approaches to improve extinguishing performance. 
The IRP has two additional comments:

5) There are several tasks associated with assessment of alternate chemicals. This critical work potentially offers the best hope for an attractive long-term solution, and it should be continued.

Recommendation: The IRP notes that the primary research organization conducting this effort is associated with a medical school. A larger role for the medical experts might expedite screening of candidate chemicals.

6) In as much as its limited resources allow, the IRP believes it important that the NGP formally assess the impact of the DDR\&E report ("Suitability of $\mathrm{CF}_{3} \mathrm{I}$ to Replace Halon 1301 as the Inerting Agent in Wing Fuel Tanks on the F-16 Aircraft") and its conclusions on both past and future NGP work, documenting any resultant changes in conclusions, recommendations, and program direction. It would be unfortunate if the conclusions of that study were to be improperly applied to cancel research in an otherwise attractive technology.

\section{Discussion:}

Evidenced throughout the 2002 ARM were the conscientious pains taken both to recognize and comprehend the previous IRP recommendations and to respond appropriately through project redirection and NGP enhancement. The IRP membership had not anticipated such a thorough attempt to accommodate all recommendations. These recommendations represented concrete actions that the IRP considered would enhance prospects for products that could be applied practically for Halon 1301 replacement in aviation fire protection. The IRP emphasizes that the its overriding interest is in the technical soundness and practical viability of the end products of the NGP. Given real-world realities of resource availability and also the inherent limits to its own technical capabilities, the IRP did not expect such complete compliance with its recommendations.

The NGP as presently constituted has funding directed mainly at new flame suppression chemicals and at improved suppressant storage and delivery. The IRP endorses this approach. In its preceding report, the IRP highlighted the apparent technical strength of the NGP program. The IRP anticipated that any near/mid-term successful replacements for Halon 1301 would likely come from higher-boiling compounds with $\mathrm{CF}_{3} \mathrm{I}$ being a particularly attractive candidate. The earlier review also highlighted possible discoveries of useful tropodegradable bromocarbons and phosphorus containing compounds. The propellant generators appeared promising provided certain practical issues could be adequately addressed. The environmental considerations were being addressed through project $4 \mathrm{~B} / 3 / 801$. The consolidated IRP position was that it was extremely important to come to grips with the effects of temperature and boiling points and airflow on the behavior of extinguisher aerosols in the cluttered engine nacelle environment. The IRP would like to see project 4B/3/801 address the issues raised in the aforementioned DDR\&E report head-on. The IRP would like the NGP to have a strong environmental basis to support the deployment of agents found in the program so that their use is not derailed by environmental arguments developed outside the program after the NGP research has been completed. 


\section{$\underline{\text { Recommendations: }}$}

The Independent Review Panel reaffirms and emphasizes the following recommendations from the 2001 IRP report, recognizing that the present NGP is reflective of their incorporation.

1) Establish a separate project on re-ignition, or elevate this issue within existing projects.

2) Expand delivery and dispersion research to include additional high-boiling-point compounds.

3) Request summation sheets on "Lessons Learned" from the principal investigators to serve as a starting point for future system design heuristics.

4) Prepare a technical information package to expedite hand-off of the portable Differential Infrared Agent Concentration Sensor to organizations involved with aircraft extinguishing system certification and testing.

5) Address directly the issue of gas-phase vapor loading from dispersed aerosols of higher boiling point extinguishing agents.

6) Initiate an interim NGP report in the form of heuristic technical rules capable of being understood and utilized by extinguishing system design and test engineers.

The Independent Review Panel adds one further recommendation.

7) Evaluate the effects of $\mathrm{CF}_{3} \mathrm{I}$ installation discharges to protect engine and APU compartments on stratospheric ozone depletion and establish a methodology applicable for this purpose to other candidate agents containing bromine or iodine. 